\title{
An overview on recent advances in the synthesis of sulfonated organic materials, sulfonated silica materials, and sulfonated carbon materials and their catalytic applications in chemical processes
}

\author{
Hashem Sharghi", Pezhman Shiri and Mahdi Aberi
}

Review

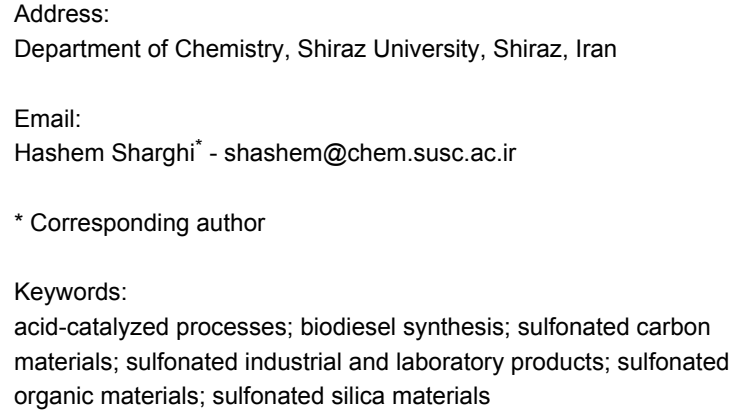

\author{
Beilstein J. Org. Chem. 2018, 14, 2745-2770. \\ doi:10.3762/bjoc. 14.253 \\ Received: 11 June 2018 \\ Accepted: 09 October 2018 \\ Published: 01 November 2018 \\ Associate Editor: D. Y.-K. Chen \\ (c) 2018 Sharghi et al.; licensee Beilstein-Institut. \\ License and terms: see end of document.
}

\begin{abstract}
This review article discusses the progress related to the synthesis and catalytic applications of sulfonated organic materials, sulfonated silica materials, and sulfonated carbon materials for industrial and laboratory products. These catalysts are widely used in acid-catalyzed processes. Most of these acid catalysts are eco-friendly, reusable, and stable. Moreover, the discovery of unique catalysts is vital for developing new, efficient, and reusable catalysts for industrial and laboratory applications. The aim of this review article is to review the recent studies (2014-2018) in the field of the utility of sulfonated organic materials, sulfonated silica materials, and sulfonated carbon materials for developing acidic catalysts.
\end{abstract}

\section{Review}

\section{Introduction}

Mineral acids (sulfuric acid, sulfonic acid, hydrochloric acid, phosphoric acid, and boric acid) as homogeneous catalysts were usually applied for the synthesis of chemical products of great industrial and laboratory importance [1].

Organic and industrial reactions are performed well by the homogeneous acid catalysts, but these procedures generate extensive amounts of toxic residues [1]. Tackling the new century increasing environmental concerns is an important tendency for 
the development of new methodologies in both developed and developing countries. In fact, the expansion of new approaches to meet the needs of modern societies without harming the environment has become a fundamental principle [2-4].

In this context, it is pertinent to note that the industrial transformations in the presence of mineral acids need expensive and corrosion-resistant equipment. These non-reusable homogeneous acid catalysts have to be neutralized after the reaction, as well $[5,6]$.

Methanesulfonic acid (MSA) and $p$-toluenesulfonic acid are commercial strong acids with $\mathrm{p} K_{\mathrm{a}}$-values of -1.9 and -2.8 , respectively, which are regularly used as simplest and more usable catalysts in chemical reactions. MSA is almost completely ionized at a concentration of $0.1 \mathrm{M}$ in an aqueous solution. The oxidative stability of organic compounds and metal ions in MSA aqueous solution is probably well recognized in the literature. Less corrosive and toxic effects and the lack of dangerous vapors make it safe to handle under normal conditions. MSA as a biodegradable chemical is decomposed within 28 days by living organisms and is part of the natural sulfur cycle. During its decomposition, only $\mathrm{CO}_{2}$ and sulfate are formed [7-10] Also, like MSA, $p$-toluenesulfonic acid ( $p$-TsOH) is nonoxidizing, low cost, and easy to handle. Its physical state is solid, making it easy to work with [11]. According to these benefits, sulfonic acids are used as novel catalysts in organic chemistry [12-16].
On the other hand, to reduce the toxicity and increase the efficiency, sulfonic acids are heterogenized on the various solid supports [17-19]. In fundamental, heterogeneous catalysis is interminably fascinating and perennially novel [20]. The few reports on sulfated solid supports are: sulfonated organic compounds [21], sulfonated silica materials [22,23], sulfonated carbon materials [5], sulfated zirconia [24], sulfated hybrid materials [25], sulfonated magnetic materials [26], sulfonated polymeric materials [27,28], sulfonated MOFs materials [29], and so on (Figure 1) [30-33].

Despite sporadic efforts, there is no detailed and updated report covering the diverse catalytic activities of sulfonated organic compounds, sulfonated silica materials, and sulfonated carbon materials in chemical processes. The current review discusses the uses of these catalysts for extensive reactions, including the synthesis of bis(indolyl)methane derivatives, $\beta$-amino carbonyl compounds, $14 H$-dibenzo[a,j]xanthene derivatives, 1,8-dioxodecahydroacridine derivatives, xanthene derivatives, pyrimido[4,5- $b]$ quinoline derivatives, spiro-isatin derivatives, spiro-acenaphthenequinone derivatives, tetrahydrobenzo $[a]-$ xanthenone derivatives, tetrahydrobenzo[ $[a]$ acridinone derivatives, 1 -amidoalkyl-2-naphthol derivatives, $2 H$-indazolo[2,1$b]$ phthalazine-1,6,11(13H)trione derivatives, quinoline derivatives, bis-coumarin derivatives, $2 H$-indazolo $[2,1-b]$ phthalazinetrione derivatives, triazolo[1,2- $a$ ]indazoletrione derivatives, tetrasubstituted imidazole derivatives, aromatic/aliphatic sulfide derivatives, and $\mathrm{N}$-substituted pyrrole derivatives. These

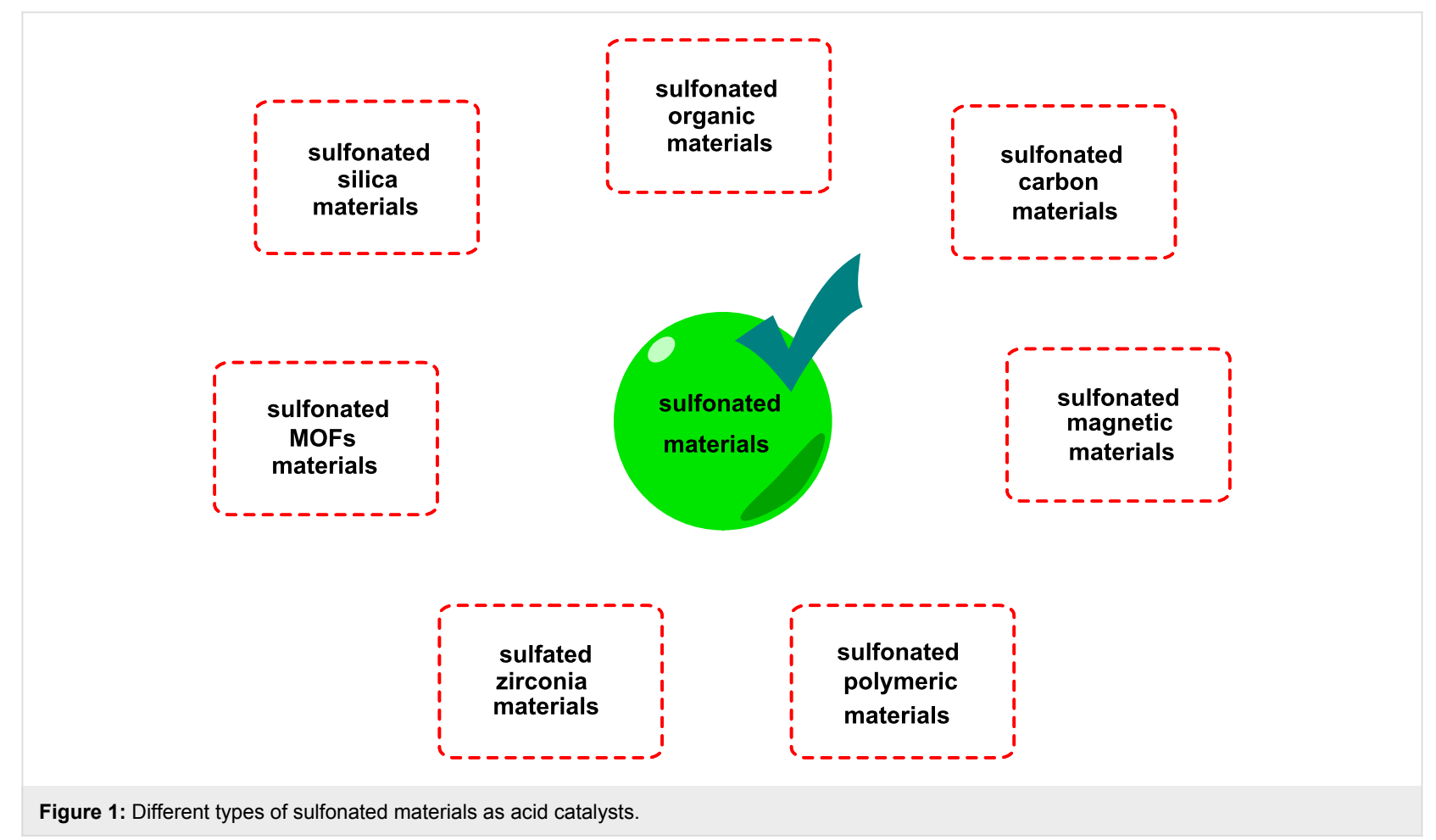


catalysts were used in cellulose hydrolysis, cellobiose hydrolysis, production of fatty acid ethyl ester, the transesterification of triglycerides with methanol, the etherification of isopentene with methanol, the esterification of palm fatty acid distillate with methanol, the dehydration of D-xylose into furfural, the production of ethyl acetate from ethanol and acetic acid, and the transesterification of palm oil with methanol into biodiesel as well.

The efficacy of these sulfonated materials as novel catalysts is well-recognized with their benefits like ease of work-up, simple separation of catalysts from products, and economic usage in industrial procedures.

We believe that a comprehensive and systematic review of the established methodologies for preparing homogeneous and heterogeneous sulfonic acid based catalysts and their applications would be effective to a broad community of scholars working in chemistry laboratories and industries.

The present paper is intended to review briefly recent studies (2014 to 2018) concerning the synthesis of various organic and chemical products catalyzed by the titled catalysts.

\section{Synthetic strategies of organic compounds containing sulfonic acid groups as a diverse class of catalysts and their uses in organic reactions}

Organic compounds containing a sulfonic acid group have extensively considered to replace traditional mineral solid and liquid acids. These catalysts have been well developed and are one of the significant branches in organic chemistry, advanced materials, and nanotechnology. They have some unique properties including stability in air and aqueous environments, ease of handling, and even reusability [34].

Ionic liquids (ILs) have been extensively reported as green solvents in organic transformations, owing to their considerable properties such as the ability to dissolve a wide range of substances, very low vapor pressure, high thermal stability, recyclability, non-flammability, low volatility, and safety. These eco-friendly materials have been applied as a new category of catalysts in some organic reactions as well. Recently, new sulfonated ionic liquids and sulfonated solid salts have been prepared and used as efficient catalysts in various chemical reactions [35-37].

In an attempt, Gogoi et al. have reported new nanostructured sulfonated catalysts (3-methyl-1-sulfo- $1 H$-imidazolium metal chlorides) containing both Lewis and Brønsted acidic sites 3-5 using the reaction of 3-methyl-1-sulfo- $1 H$-imidazolium chloride (2) with $\mathrm{FeCl}_{3}, \mathrm{ZnCl}_{2}$ or $\mathrm{CuCl}$ in an inert atmosphere for $2 \mathrm{~h}$. The 3-methyl-1-sulfo- $1 \mathrm{H}$-imidazolium metal chlorides $[\mathrm{Msim}]\left[\mathrm{FeCl}_{4}\right](\mathbf{3}),[\mathrm{Msim}]\left[\mathrm{ZnCl}_{3}\right](\mathbf{4})$, and $[\mathrm{Msim}]\left[\mathrm{CuCl}_{2}\right](\mathbf{5})$ were examined for the selective synthesis of bis(indolyl)methane derivatives $\mathbf{8}$ and the results showed that more acidic $[\mathrm{Msim}]\left[\mathrm{FeCl}_{4}\right]$ catalyst $\mathbf{3}$ produces excellent yields of products 8 with only $5 \mathrm{~mol} \%$ loading. However, $10 \mathrm{~mol} \%$ of the less acidic $[\mathrm{Msim}]\left[\mathrm{ZnCl}_{3}\right](\mathbf{4})$ and $[\mathrm{Msim}]\left[\mathrm{CuCl}_{2}\right](\mathbf{5})$ catalysts were applied to obtain the desired products $\mathbf{8}$ with excellent yields (Scheme 1). A recyclability study indicated three consecutive runs with a similar efficiency [38].

Other researchers designed and synthesized a new number of 1,3-disulfoimidazolium transition metal chlorides including $[\mathrm{Dsim}]_{2}\left[\mathrm{ZnCl}_{4}\right](\mathbf{1 1}),[\mathrm{Dsim}]\left[\mathrm{FeCl}_{4}\right](\mathbf{1 2})$, and $[\mathrm{Dsim}]_{2}\left[\mathrm{NiCl}_{4}\right]$ (13) as Brønsted-Lewis acidic solid materials. All these catalysts were reported as reusable and efficient catalysts for the multicomponent Mannich-type synthesis of $\beta$-aminocarbonyl products $\mathbf{1 6}$ in suitable times and yields (Scheme 2). To check the reusability of the catalysts, the reaction between benzaldehyde, aniline, and acetophenone in $5 \mathrm{mmol}$ scale in ethanol was chosen. All catalysts were recycled three times using filtration of product solution in chloroform [39].

1,3-Disulfo-1 $H$-imidazolium carboxylate ILs [Dsim]-[carboxylate] 17-19 were synthesized using environmentally benign reactions between 1,3-disulfo- $1 H$-imidazolium chloride [Dsim][Cl] (10) and three different carboxylic acids $\left(\mathrm{CH}_{3} \mathrm{COOH}, \mathrm{CCl}_{3} \mathrm{COOH}, \mathrm{CF}_{3} \mathrm{COOH}\right)$. The more acidic [DISM] [CCl $\left.{ }_{3} \mathrm{COO}\right]$ (18) and [Dsim] $\left[\mathrm{CF}_{3} \mathrm{COO}\right]$ (19) ILs were utilized as recyclable, efficient, and eco-benign catalysts for the three-component one-pot condensations towards a variety of 1,8-dioxodecahydroacridine derivatives 22 and $14 \mathrm{H}$ dibenzo $[a, j]$ xanthene derivatives $\mathbf{2 4}$ in short reaction times under solvent-free or water medium with good to excellent yields (Scheme 3) [40].

Some results for these catalytic systems were summarized. The reaction between dimedone (20), aldehydes $\mathbf{7}$, and ammonium chloride (21) produced excellent yields of 1,8-dioxodecahydroacridine derivatives 22 within $10-15$ minutes at $80-100{ }^{\circ} \mathrm{C}$ using $25 \mathrm{~mol} \%$ of [Dsim] $\left[\mathrm{CCl}_{3} \mathrm{COO}\right](\mathbf{1 8})$ or [Dsim] $\left[\mathrm{CF}_{3} \mathrm{COO}\right]$ (19) ILs in absence of any solvent or in $1.0 \mathrm{~mL}$ of water. On the other hand, 1,8-dioxodecahydroacridine derivatives $\mathbf{2 4}$ were synthesized at $80-100{ }^{\circ} \mathrm{C}$ with good to excellent yields using $25 \mathrm{~mol} \%$ of [Dsim] $\left[\mathrm{CCl}_{3} \mathrm{COO}\right](\mathbf{1 8})$ or $[\mathrm{Dsim}]\left[\mathrm{CF}_{3} \mathrm{COO}\right]$ (19) ILs in absence of any solvent. The [Dsim] $\left[\mathrm{CCl}_{3} \mathrm{COO}\right](\mathbf{1 8})$ and [Dsim] $\left[\mathrm{CF}_{3} \mathrm{COO}\right]$ (19) ILs showed good recyclability and the catalysts were reused for three consecutive runs. In this case, the desired products were extracted by dry dichloromethane 


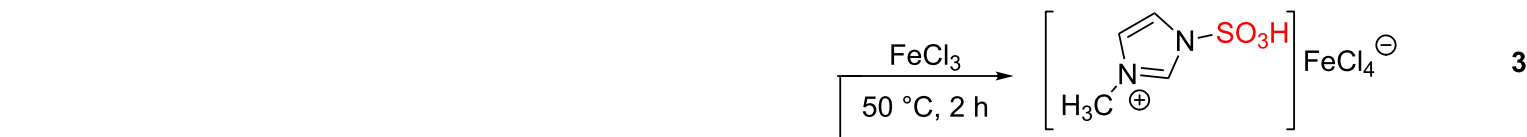

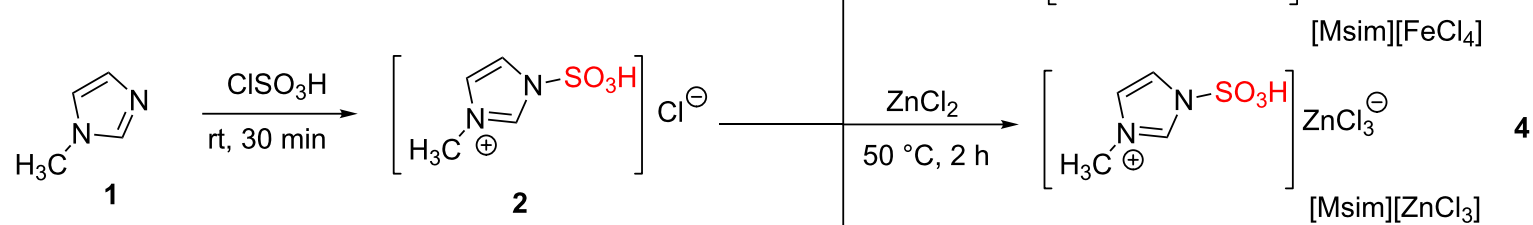

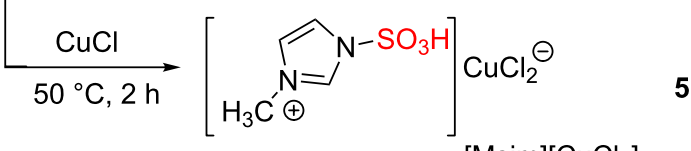

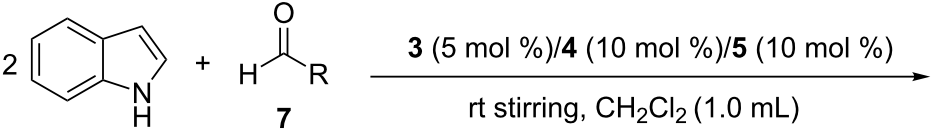
6<smiles>[R]C(c1c[nH]c2ccccc12)c1c[nH]c2ccccc12</smiles>

$\mathrm{R}=\mathrm{OPh}, 4-\mathrm{MeOPh}, 4-\mathrm{NO}_{2} \mathrm{Ph}, 4-\mathrm{CIPh}, \mathrm{C}_{6} \mathrm{H}_{5}-\mathrm{CH}=\mathrm{CH}-\mathrm{Ph}$, 2-naphthyl, 4- $\mathrm{CH}_{3} \mathrm{Ph}$

times of reaction in presence of catalyst $3: 15-30$ min 1 yields of reaction in presence of catalyst $3: 97-98 \%$ times of reaction in presence of catalyst 4: 15-60 min $\quad$ yields of reaction in presence of catalyst 4: $96-97 \%$,

times of reaction in presence of catalyst 5: $30-90 \mathrm{~min}$ : $:$ yields of reaction in presence of catalyst 5: 94-97\%:

Scheme 1: Synthetic route of 3-methyl-1-sulfo-1H-imidazolium metal chloride ILs and their catalytic applications in the synthesis of bis(indolyl)methane derivatives.
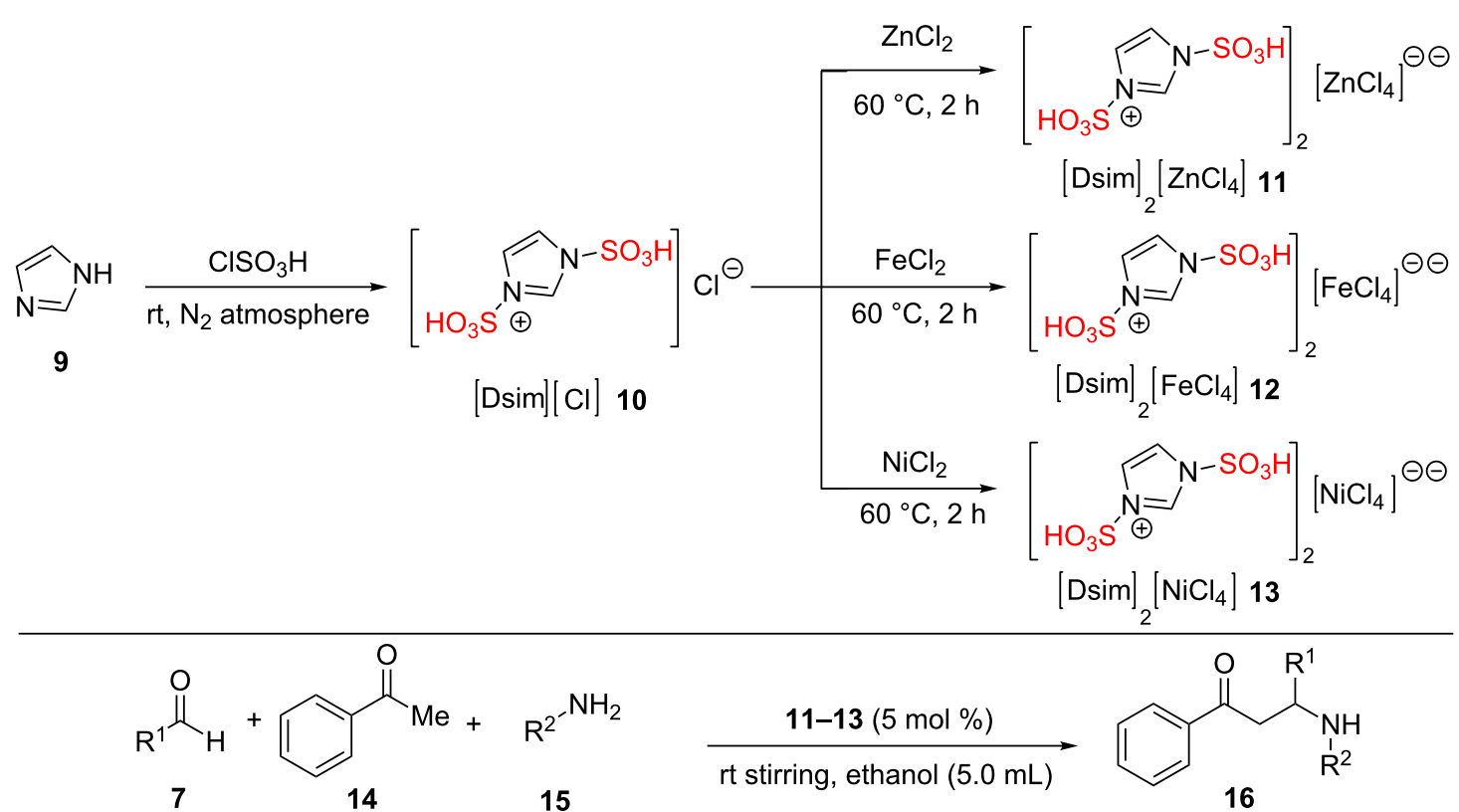

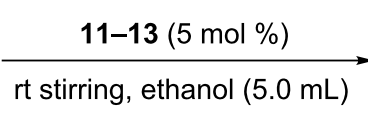

15<smiles>[R]NC([R])CC(=O)c1ccccc1</smiles>

16

$\mathrm{R}^{1}=\mathrm{Ph}, 4-\mathrm{CIPh}, 4-\mathrm{MePh}, 3-\mathrm{BrPh}$

$\mathrm{R}^{2}=\mathrm{Ph}, 4-\mathrm{CIPh}, 4-\mathrm{NO}_{2} \mathrm{Ph}$

times of reaction in presence of catalyst 11: $70-90$ min 1 yields of reaction in presence of catalyst 11: 82-90\%,

I times of reaction in presence of catalyst 12: 30-60 min $\quad$ yields of reaction in presence of catalyst 12: $85-96 \%$ '

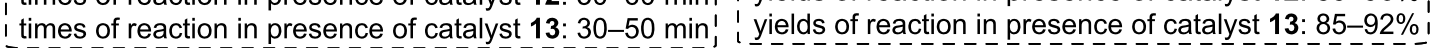

Scheme 2: Synthetic route of 1,3-disulfo-1H-imidazolium transition metal chloride ILs and their catalytic applications in the synthesis of $\beta$-aminocarbonyl compounds. 


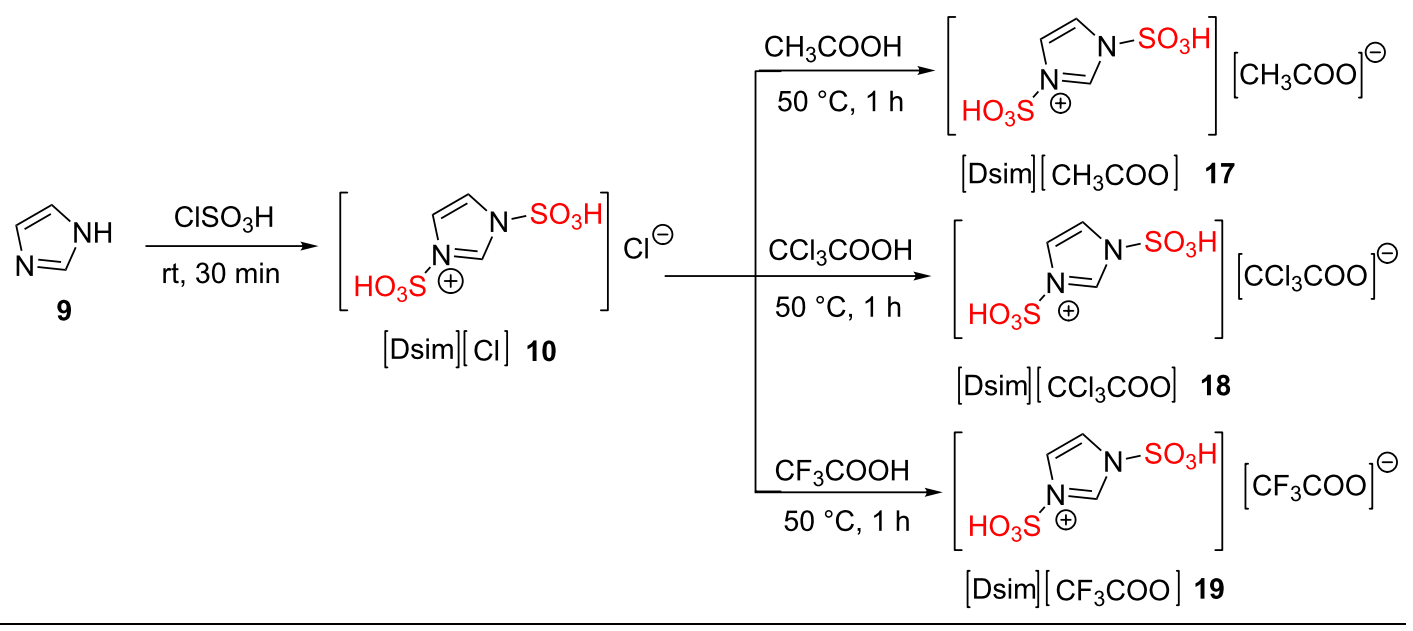

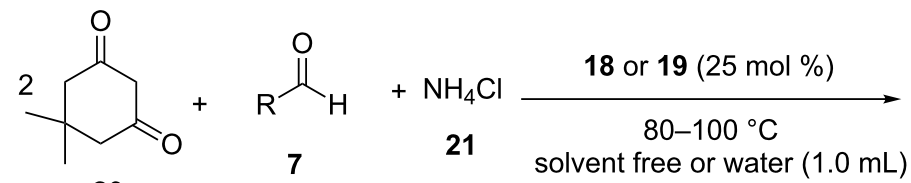

20<smiles>[R]C1C2=C(CC(C)(C)CC2=O)NC2=C1C(=O)CC(C)(C)C2</smiles>

22

$\mathrm{R}=\mathrm{Ph}, 4-\mathrm{MeOPh}, 4-\mathrm{NO}_{2} \mathrm{Ph}, 4-\mathrm{ClPh}, \mathrm{Ph}-\mathrm{CH}=\mathrm{CHPh}, 4-\mathrm{MePh}$, naphthyl, $\mathrm{H}$

times of reaction in presence of catalyst 18: 10-40 $\mathrm{min}$
times of reaction in presence of catalyst 19: 10-40 min<smiles>Oc1ccc2ccccc2c1</smiles>

23

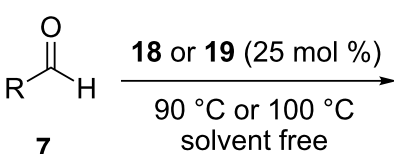
solvent free

$\mathrm{R}=\mathrm{Ph}, 4-\mathrm{MeOPh}, 4-\mathrm{NO}_{2} \mathrm{Ph}, 4-\mathrm{ClPh}, \mathrm{Ph}-\mathrm{CH}=\mathrm{CHPh}$, 4-MePh, naphthyl, $\mathrm{H}$

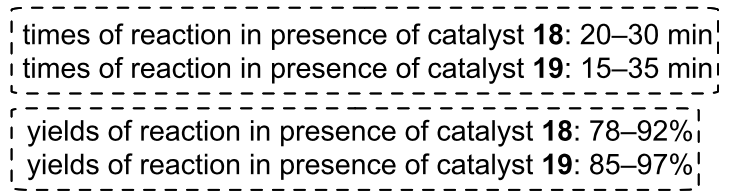

Scheme 3: Synthetic route of 1,3-disulfoimidazolium carboxylate ILs and their catalytic applications in the synthesis of $14 \mathrm{H}$-dibenzo[a,j]xanthene derivatives and 1,8-dioxodecahydroacridine derivatives.

from the ionic liquid medium $\mathbf{1 8}$ or $\mathbf{1 9}$ and then the ionic liquids 18 or 19 were again applied for next runs.

Shirini et al. have reported a series of procedures for the synthesis of sulfonated materials and their applications for one-pot multicomponent reactions. This research group has reported a new route for the preparation of $\mathrm{bi}-\mathrm{SO}_{3} \mathrm{H}$ ionic liquids based on 2,2'-bipyridine 25 using the reaction of chlorosulfonic acid and $2,2^{\prime}$-bipyridine as well as its application for the synthesis of the various xanthene derivatives 24, 27, and 28 [41]. In another study, the sulfonated imidazole $\mathbf{2 6}$ was prepared via the drop- wise addition of chlorosulfonic acid to a stirred solution of imidazole in dry $\mathrm{CH}_{2} \mathrm{Cl}_{2}$ in an ice bath. In the next step, sulfuric acid $98 \%$ was added dropwise to the reaction mixture containing the sulfonated imidazole at room temperature to obtain 1,3disulfo- $1 \mathrm{H}$-imidazolium hydrogen sulfate $[\mathrm{Dsim}] \mathrm{HSO}_{4}(\mathbf{2 6})$ as a viscous pale yellow oil catalyst. [Dsim] $\mathrm{HSO}_{4}(\mathbf{2 6})$ has been also employed as a reusable and efficient catalyst for the onepot multicomponent synthesis of various xanthene derivatives 24, 27, and 28 and pyrimido[4,5-b] quinoline derivatives 30 under mild and green conditions (Scheme 4) [42-44]. Easy preparation of the catalyst, easy reusability of the catalyst, easy 

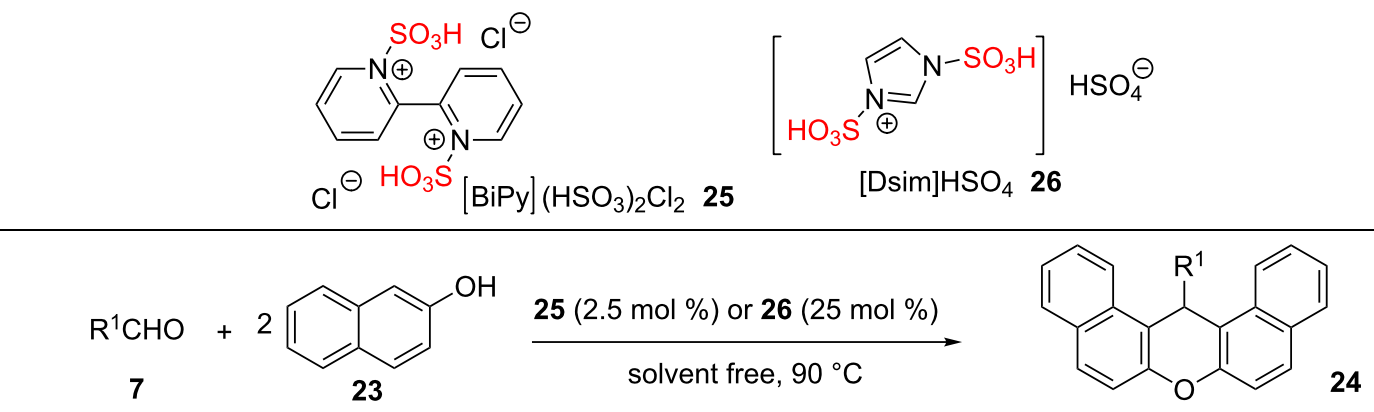

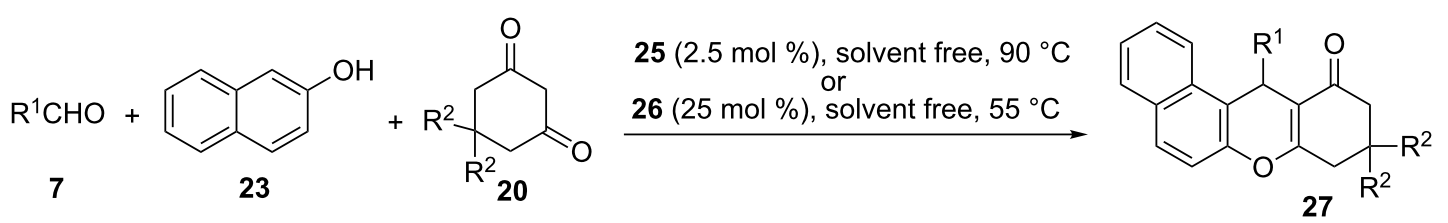

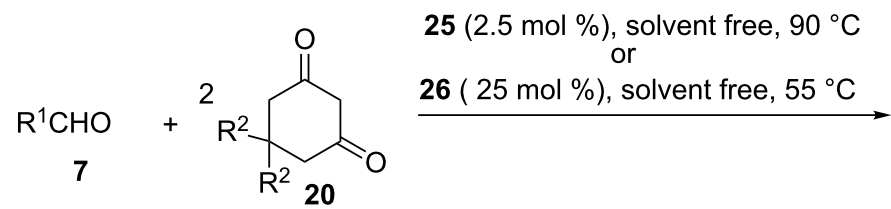<smiles>[R]C1CC([R])([R])CC2=C1C([R])C1=C(CC([R])([R])CC1=O)O2</smiles>

$\mathrm{R}^{1}=\mathrm{X}-\mathrm{Ph}(\mathrm{x}=$ electron donating and electron withdrawing groups) $\mathrm{R}^{2}=\mathrm{H}, \mathrm{Me}$

times of reaction in presence of catalyst $25: 1-50$ min $\quad$ yields of reaction in presence of catalyst $25: 80-98 \%$; times of reaction in presence of catalyst $26: 2-35 \mathrm{~min}$, yields of reaction in presence of catalyst 26: $86-95 \%$ :<smiles>CN1C(=O)CC([NH3+])N(C)C1=O</smiles>

29<smiles>[R]C(=O)[18F]</smiles>

7<smiles>[R]C1([R])CC(=O)CC(=O)C1</smiles>

20<smiles>CC(C)(C)C(=O)O</smiles>

ethanol, $70^{\circ} \mathrm{C}$<smiles>[R]C1C2=C(CC([R])([R])CC2=O)Nc2c1c(=O)n(C)c(=O)n2C</smiles>

$\mathrm{R}^{1}=\mathrm{X}-\mathrm{Ph}(\mathrm{x}=$ electron donating and electron withdrawing groups)

$\mathrm{R}^{2}=\mathrm{H}, \mathrm{Me}$

times of reaction in presence of catalyst 26 : $15-35$ min

yields of reaction in presence of catalyst 26: $85-92 \%$

Scheme 4: Synthetic route of $[\mathrm{BiPy}]\left(\mathrm{HSO}_{3}\right)_{2} \mathrm{Cl}_{2}$ and [Dsim] $\mathrm{HSO}_{4}$ ILs and their catalytic applications for the synthesis of pyrimido[4,5-b]quinoline derivatives and xanthene derivatives.

handling, mild reaction conditions, low cost, excellent yields, short reaction times, and eco-friendly are some of the advantages of this work.

An efficient, practical, and convenient strategy which is concerned with the construction of nanosized 4,4'-(butane-1,4diyl)bis(1-sulfo-1,4-diazabicyclo[2.2.2] octane-1,4-diium) chloride $\left(\mathrm{C}_{4}\left(\mathrm{DABCO}-\mathrm{SO}_{3} \mathrm{H}\right)_{2} \cdot 4 \mathrm{Cl}, \mathbf{3 1}\right)$ and its applications in the synthesis of spiro-oxindole derivatives $\mathbf{3 6}$ and $\mathbf{3 7}$ was described. $\mathrm{C}_{4}\left(\mathrm{DABCO}-\mathrm{SO}_{3} \mathrm{H}\right)_{2} \cdot 4 \mathrm{Cl} 31$ acted as an efficient, cheap, and reusable nanocatalyst for synthesis of 2-amino- $4 H$ pyran derivatives $\mathbf{3 6}$ and $\mathbf{3 7}$ from active carbonyl compounds (e.g., isatins 32, acenaphthoquinone (33), and aldehydes 38), a variety of $\mathrm{C}-\mathrm{H}$ activated acids (cyclohexane-1,3-dione (20a), 5,5-dimethylcyclohexane-1,3-dione (20b), 2-naphthol (23), ethyl acetoacetate (34a), 4-hydroxycoumarin (34b), triacetic acid lactone (34c), and 1-naphthol (34d)), and malononitrile (35) in water at $90{ }^{\circ} \mathrm{C}$. Isatin (32) and acenaphthenequinone (33) were reacted with $\mathrm{C}-\mathrm{H}$ activated acids $20 \mathbf{a}, \mathbf{b}, \mathbf{2 3}$, and $\mathbf{3 4 a}-\mathbf{c}$ and malononitrile (35) to form the corresponding spiroisatin derivatives $\mathbf{3 6}$ and spiro-acenaphthenequinone derivatives 37 under mild and homogeneous conditions (Scheme 5). After this successful application, catalyst $\mathbf{3 1}$ was tested in the synthesis of bis(2-amino-4H-pyran) derivatives 39-44 via a one-pot multicomponent reaction of dialdehydes $\mathbf{3 8}$ (instead of isatin and acenaphthenequinone substrates), a variety of $\mathrm{C}-\mathrm{H}$ 

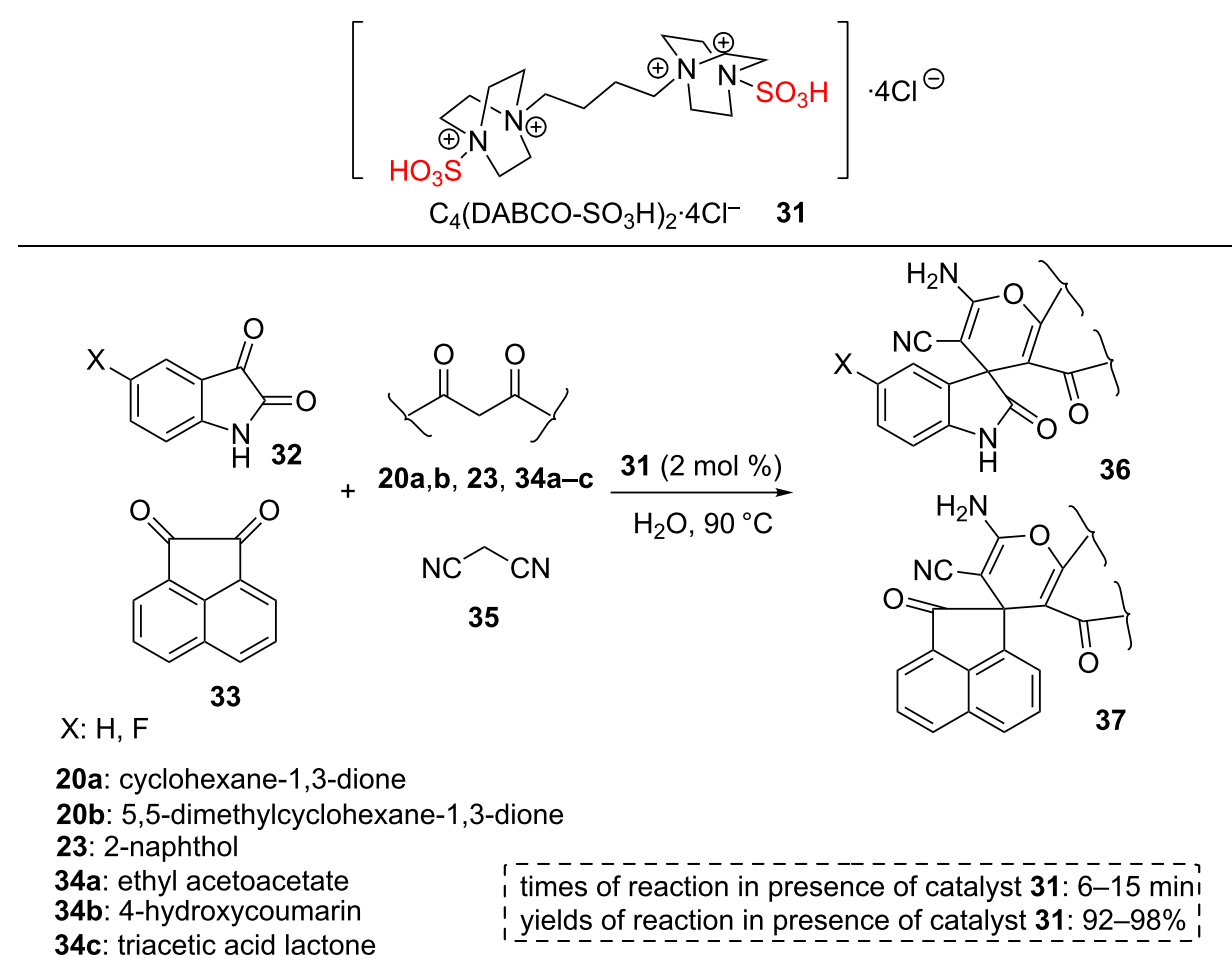

Scheme 5: The catalytic applications of $\left(\mathrm{C}_{4}\left(\mathrm{DABCO}-\mathrm{SO}_{3} \mathrm{H}\right)_{2} \cdot 4 \mathrm{Cl}\right) \mathrm{IL}$ for the synthesis of spiro-isatin derivatives and spiro-acenaphthenequinone derivatives.

activated acids $20 \mathbf{a}, \mathbf{b}, \mathbf{2 3}, \mathbf{3 4 a}-\mathbf{c}$ and malononitrile (35) under the same reaction conditions. The observations showed that bis(2-amino-4H-pyran) derivatives 39-44 are constructed in excellent yields during very short reaction times with a higher amount of the catalyst ( $4 \mathrm{~mol} \%$, Scheme 6 ). The recyclability of this homogeneous catalytic system was also studied by the reaction of isatin, malononitrile, and dimedone. After completion of the reaction, the reaction mixture was filtered and the same substrates were added directly to the filtrate solution containing the homogeneous catalytic system. There is no need to add solvent as well. The catalytic system worked for nine runs without considerable loss in its activity [45].

In 2017, the synthesis of $N, N$-disulfo-1,1,3,3-tetramethylguanidinium carboxylate ILs $\mathbf{4 7 a - c}$ through reactions between $N, N$ disulfotetramethylguanidinium chloride (46) with three carboxylic acids $\left(\mathrm{AcOH}, \mathrm{CCl}_{3} \mathrm{COOH}\right.$, and $\left.\mathrm{CF}_{3} \mathrm{COOH}\right)$ in hexane at $60{ }^{\circ} \mathrm{C}$ for $45-60 \mathrm{~min}$ was achieved and reported. The chemical structures of new $-\mathrm{SO}_{3} \mathrm{H}$ functionalized ILs were confirmed by IR, ${ }^{1} \mathrm{H}$ NMR, ${ }^{13} \mathrm{C}$ NMR, and elemental analyses data The NMR spectra provided evidence for resonating structures of $\mathrm{N}, \mathrm{N}$-disulfotetramethylguanidinium cations. The ${ }^{1} \mathrm{H}$ NMR spectrum displayed all protons of two $-\mathrm{NMe}_{2}$ groups as a singlet in the region of 3-3.2 ppm. On the other hand, the carbon chemical shift of $\mathrm{C}=\mathrm{N}$ appeared around $134.7 \mathrm{ppm}$ and
$119.9 \mathrm{ppm}$ attributed to two types of the chemical environment of the $\mathrm{C}=\mathrm{N}$ carbon [46].

The three-component synthesis of tetrahydrobenzo $[a]$ xanthenone derivatives 48a and the four component synthesis of tetrahydrobenzo $[a]$ acridinone derivatives $\mathbf{4 8 b}$ were performed with good to excellent yields under solvent-free conditions at $75-85^{\circ} \mathrm{C}$ within short reaction times using the higher acidic/ stable ILs containing trichloroacetate and trifluoroacetate anions 47b,c. Following this method, various aromatic aldehydes bearing electron-withdrawing or donating groups $\left(-\mathrm{NO}_{2},-\mathrm{Cl},-\mathrm{OMe}\right.$, -Me) 7 have been used to prepare the desired products in 85-95\% yields. Aliphatic aldehydes produced complex mixtures of products using these homogeneous catalysts (Scheme 7). Significantly, IL catalysts $47 \mathbf{b}, \mathbf{c}$ could be extracted from the reaction mixture for six consecutive cycles. In all runs, IL catalysts $\mathbf{4 7 b}, \mathbf{c}$ showed excellent catalytic activity. The FTIR spectra of two of these reused ILs after the 6th run and the fresh ILs have been used to prove the retention of their catalytic activity [46].

Khazaei et al. prepared 3-methyl-1-sulfo- $1 H$-imidazolium tetrachloroferrate $\left([\mathrm{Msim}] \mathrm{FeCl}_{4}, 3\right)$ as a nanostructured catalyst via the reaction of 3-methyl-1-sulfon- $1 H$-imidazolium chloride with dry $\mathrm{FeCl}_{3}$. After stirring the starting materials for 


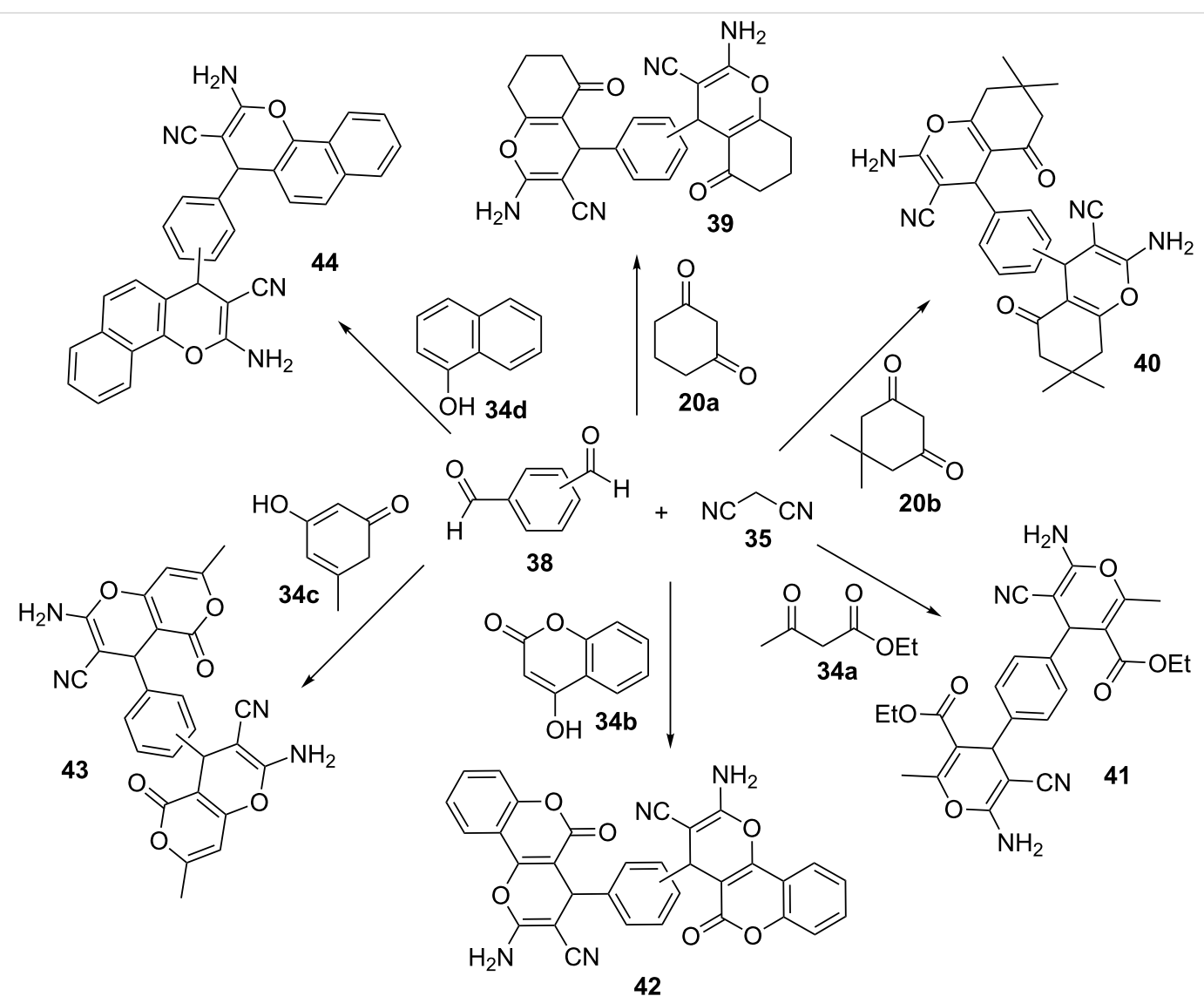

Scheme 6: The catalytic applications of $\left(\mathrm{C}_{4}\left(\mathrm{DABCO}-\mathrm{SO}_{3} \mathrm{H}\right)_{2} \cdot 4 \mathrm{Cl}\right) \mathrm{IL}$ for the synthesis of bis 2-amino-4H-pyran derivatives.

$$
\text { [DSTMG][Cl] 46 }
$$
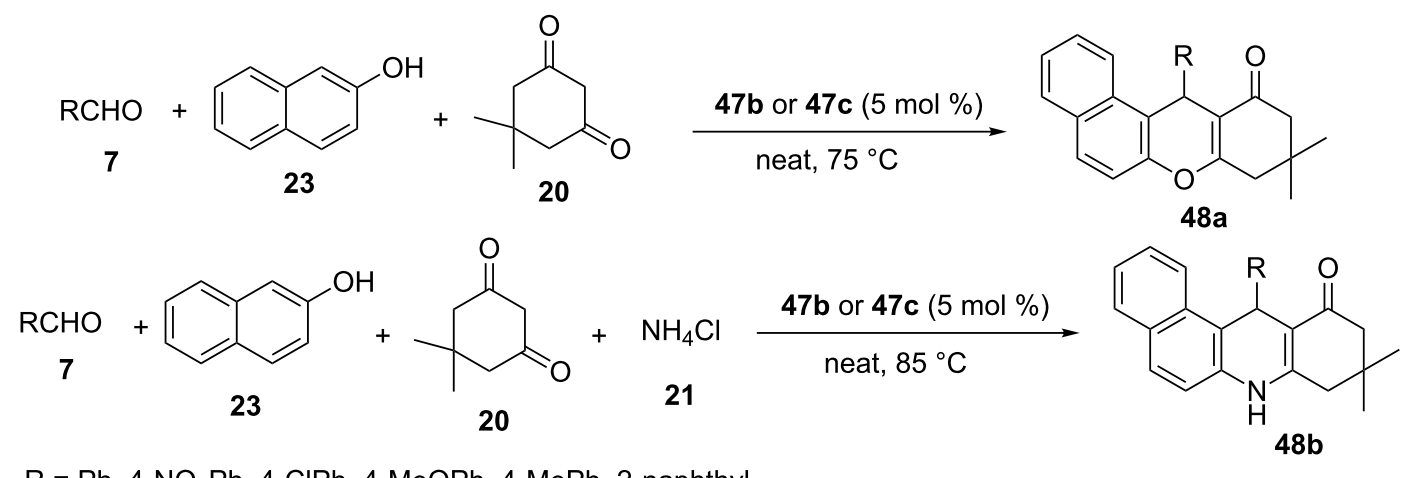

$\mathrm{R}=\mathrm{Ph}, 4-\mathrm{NO}_{2} \mathrm{Ph}, 4-\mathrm{CIPh}, 4-\mathrm{MeOPh}, 4-\mathrm{MePh}, 2-$ naphthyl

times of reaction in presence of catalyst $47 \mathrm{~b}$ : $12-18$ min, yields of reaction in presence of catalyst $47 \mathrm{~b}$ : $85-93 \%$

times of reaction in presence of catalyst 47c: $10-14 \mathrm{~min}$, yields of reaction in presence of catalyst 47c: $88-95 \%$ ।

Scheme 7: The synthetic route of $N, N$-disulfo-1,1,3,3-tetramethylguanidinium carboxylate ILs and their catalytic applications for the synthesis of tetrahydrobenzo[a]xanthenone derivatives and tetrahydrobenzo[a]acridinone derivatives. 
60 minutes at $70{ }^{\circ} \mathrm{C}$, a dark green soiled salt was obtained in $98 \%$ yield. The catalyst was characterized by different analyses. The FE-SEM images exhibited that the particles of the catalyst are in nano size. According to XRD pattern, the crystallite size is at about $13.7 \mathrm{~nm}$. The IR spectrum confirmed the presence of the $\mathrm{O}-\mathrm{H}$ stretching of the $-\mathrm{SO}_{3} \mathrm{H}$ group at $2650-3550 \mathrm{~cm}^{-1}$ as well as the vibrational modes of $\mathrm{N}-\mathrm{SO}_{2}$ and $\mathrm{O}-\mathrm{SO}_{2}$ bonds at $1062 \mathrm{~cm}^{-1}$ and $1179 \mathrm{~cm}^{-1}$, respectively.

The catalyst 3 was found to be effective in the tandem reaction between $\beta$-naphthol (23), aromatic aldehydes 7, and amide derivatives 49 at $110^{\circ} \mathrm{C}$ under solvent-free conditions. The products were produced in very short reaction times and recrystallized in ethanol to give pure 1-amidoalkyl-2-naphthols $\mathbf{5 0}$ (Scheme 8 ). The reusability of the ionic liquid catalyst 3 was also studied. For this purpose, warm acetone was used to extract the products from the catalyst. The catalyst showed good catalytic activity for four successive runs [47].

Tayebee and co-workers prepared 3-sulfo-imidazolopyridinium hydrogen sulfate $\left([\mathrm{Simp}] \mathrm{HSO}_{4}, \mathbf{5 3}\right)$ as a new natural ionic liquid by the reaction between caffeine (51) as a natural, inexpensive, and available substance and chlorosulfonic acid for the first time. The authors proposed that the high Brønsted acidity of the catalyst arises mainly from hydrogen bonds between the two $-\mathrm{SO}_{3} \mathrm{H}$ groups. The catalyst $\mathbf{5 3}$ was studied by different analyses including FTIR, ${ }^{1} \mathrm{H}$ NMR, ${ }^{13} \mathrm{C}$ NMR, UV-vis, and fluorescence spectra. Then, catalyst $\mathbf{5 3}$ was utilized for the synthesis of $2 H$-indazolo[2,1- $b]$ phthalazine-1,6,11(13H)-trione derivatives 55 via a one-pot, three-component reaction of phthalhydrazide (54), aldehydes $\mathbf{7}$, and dimedone (20) or cyclohexane-1,3-dione (for $\mathrm{R}^{3}=\mathrm{H}, \mathbf{2 0}$ ) under solvent-free conditions (Scheme 9). To check the reusability of catalyst $\mathbf{5 3}$, the reaction mixture was extracted with hot ethyl acetate. The residue was washed with hot ethyl acetate to afford the purely recycled catalyst. The catalyst $\mathbf{5 3}$ exhibited excellent reusability for 6 runs. Short reaction times, good to excellent product yields, a scaled-up synthesis and usage of the natural based ionic liquid as well as the high reusability of the catalyst are the advantages of this catalytic method [48].

Khaligh et al. [49] have synthesized two novel binuclear sulfonic-functionalized ionic liquids $\mathbf{5 6}$ and $\mathbf{5 7}$ with solventcatalyst abilities for the synthesis of bis(indolyl)methanes 8, 59, and 60 under mild reaction conditions. The new ionic liquids $\mathbf{5 6}$ and $\mathbf{5 7}$ consist of a four-carbon spacer and an acidic anion. The structures of BBSI-Cl (56) and $\mathrm{BBSI}_{-} \mathrm{HSO}_{4}(\mathbf{5 7})$ were characterized using FTIR, MS, ${ }^{1} \mathrm{H}$ and ${ }^{13} \mathrm{C}$ NMR. The FTIR spectra of BBSI-Cl (56) and $\mathrm{BBSI}^{-H_{S O}} \mathrm{H}_{4}(\mathbf{5 7})$ displayed a broad peak at the range of $3500-3200 \mathrm{~cm}^{-1}$ related to stretching vibration of -OH groups in $-\mathrm{SO}_{3} \mathrm{H}$ and $\mathrm{HSO}_{4}{ }^{-}$scaffolds and moisture. The peaks positioned at $3144,3152,2925,2878$ and $2854 \mathrm{~cm}^{-1}$ are related to $\mathrm{C}-\mathrm{H}$ stretching vibrations of the aliphatic chain in BBSI-Cl (56) and BBSI-HSO 4 (57). Two peaks due to $\mathrm{C}=\mathrm{C}$ and $\mathrm{C}=\mathrm{N}$ were observed at 1680 and $1540 \mathrm{~cm}^{-1}$. The bands at the range of $1200-1000 \mathrm{~cm}^{-1}$ are due to $\mathrm{SO}_{2}$ asymmetric and symmetric vibrations.

A variety of aryl or heterocyclic aldehydes $\mathbf{7 , 3 8}$, and $\mathbf{5 8}$ were reacted with indole or 5-bromo- $1 H$-indole (6a) to synthesize the desired products 8,59 , and $\mathbf{6 0}$ in the presence of these solventcatalyst ILs 56 and 57. The catalytic efficiency of these two ILs (containing chloride or hydrogen sulfate counter anions) were screened in comparison with previously reported sulfonic acidfunctionalized ILs derived from pyrazinium, piperazinium, benzimidazolium, and imidazolium as a cation part and chloride as an anion part (Scheme 10). Because of the presence of acidic anion, the catalytic activity of IL containing $\mathrm{HSO}_{4}{ }^{-}$as an anion (BBSI- $\mathrm{HSO}_{4}$ ) was higher than IL containing $\mathrm{Cl}^{-}$as an anion (BBSI-Cl). To increase the efficiency of the current procedure, the authors estimated the reusability of the solvent-catalyst ILs. The catalysts were removed with water from the reaction mixture. However, this way did not work in some cases, and the organic products were extracted from the ILs by non-<smiles>Oc1ccc2ccccc2c1</smiles>

23<smiles>[NH3+]C(=O)c1ccccc1</smiles>

49<smiles>[R]C=O</smiles>

7

$\mathrm{R}=\mathrm{Ph}, 2-\mathrm{FPh}, 2,3-\mathrm{CIPh}, 2,4-\mathrm{CIPh}, 2-\mathrm{BrPh}$, 3-BrPh, 4-BrPh, 4-Cl-3- $\mathrm{NO}_{2} \mathrm{Ph}, 4-\mathrm{MePh}$, 2- $\mathrm{NO}_{2} \mathrm{Ph}, 3-\mathrm{NO}_{2} \mathrm{Ph}, 1$-naphthyl, 2-naphthyl

times of reaction in presence of catalyst $3: 2-6$ min yields of reaction in presence of catalyst 3: $85-95 \%$
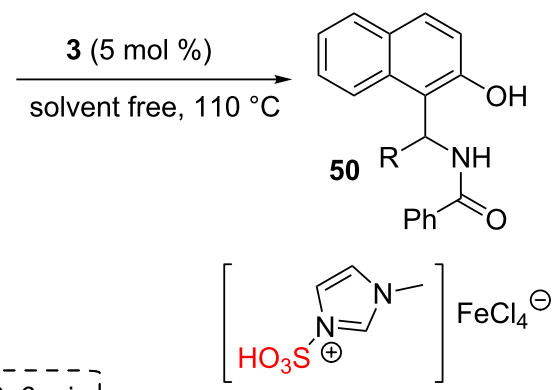

$[\mathrm{Msim}] \mathrm{FeCl}_{4} 3$ 

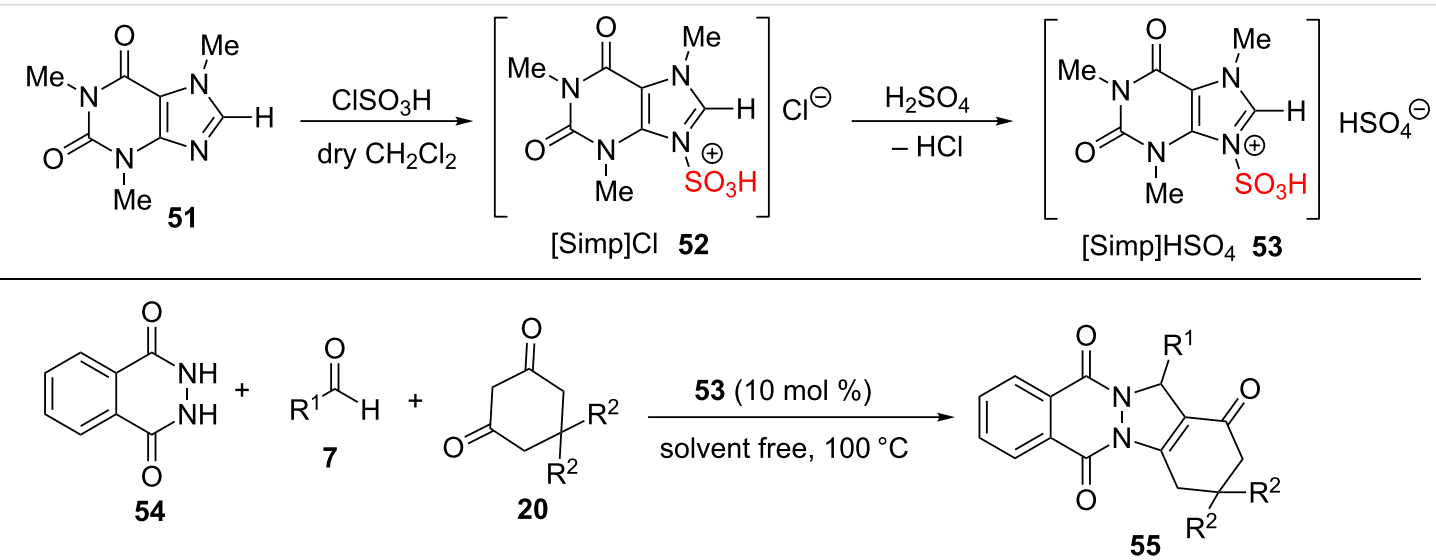

$\mathrm{R}^{1}=$ electron withdrawing and electron releasing groups, halogen on phenyl ring, aliphatic chain $\mathrm{R}^{2}=\mathrm{Me}, \mathrm{H}$

times of reaction in presence of catalyst $53: 10-120$ min

yields of reaction in presence of catalyst 53: $33-87 \%$

Scheme 9: The synthetic route of 3-sulfo- $1 \mathrm{H}$-imidazolopyrimidinium hydrogen sulfate IL and its catalytic application for the synthesis of $2 H$-indazolo[2,1-b]phthalazine-1,6,11(13H)-trione derivatives.<smiles></smiles>

BBSI-Cl 56<smiles></smiles>

BBSI-HSO 45

binuclear sulfonic-functionalized ionic liquids<smiles>[Z]C(=O)c1ccc[Y4]1C=O</smiles><smiles>[Y]c1ccc2[nH]ccc2c1</smiles>

$\mathrm{R}^{1}=\mathrm{Ph}, 4-\mathrm{MePh}, 4-\mathrm{MeOPh}, 4-\mathrm{CIPh}, 2-\mathrm{CIPh}$,

4- $\mathrm{NO}_{2} \mathrm{Ph}, 3-\mathrm{NO}_{2} \mathrm{Ph}, 4$-acetyl-Ph

\section{$\mathrm{X}=\mathrm{S}$ and $\mathrm{O}$}

times of reaction in presence of catalyst 56 and $\mathbf{5 7}: 20 \mathrm{~min}$

yields of reaction in presence of catalyst 56: $65-96 \%$

yields of reaction in presence of catalyst 57 : $72-96 \%$<smiles>[R]c1c[nH]c2ccccc12</smiles><smiles>[X]c1ccccc1C(c1c[nH]c2ccccc12)c1c[nH]c2ccccc12</smiles>

59<smiles>c1ccc2c(C(c3ccc(C(c4c[nH]c5ccccc45)c4c[nH]c5ccccc45)cc3)c3c[nH]c4ccccc34)c[nH]c2c1</smiles>

Scheme 10: The results for the synthesis of bis(indolyl)methanes and di(bis(indolyl)methyl)benzenes in the presence of disulfonic-functionalized ILs.

polar organic solvents. The organic products were extracted from the ILs by ethyl acetate or ether to give the recycled catalyst and the products. The remained ILs were concentrated and recharged with new starting materials for another run. The ILs showed the excellent catalytic activity for three consecutive runs. Finally, this research group explored the structure of reused $\mathrm{BBSI}_{-} \mathrm{HSO}_{4}(\mathbf{5 6})$ and $\mathrm{BBSI}-\mathrm{Cl}(\mathbf{5 7})$ ILs after the third run by use of ${ }^{1} \mathrm{H}$ NMR spectra. The ILs showed no noteworthy change in their structures. The advantages of these catalytic systems are using solvent-catalyst ILs, mild reaction conditions, 
diverse products, short reaction times, good reusability, good to excellent yields, and producing bis-products [49].

Amarasekara and co-workers described the effect of using sulfonic acid group functionalized ILs as catalysts in the hydrolysis of cellulose [50]. After this study, this research group reported that these sulfonic acid group functionalized ILs can also be applied in aqueous phase [51]. On the other hand, it has been proved that adding a catalytic amount of metal salts can slightly increase product yields [52]. So this research group prepared 1-(3-sulfopropyl)-3-methyl-1 $H$-imidazolium chloride acidic IL 63 and the catalytic activity of this IL with or without a range of metal chloride salts was explored in the hydrolysis of cellulose in water. The best result was observed when $\mathrm{Mn}^{2+}$ was used in aqueous media at $170{ }^{\circ} \mathrm{C}$; without using $\mathrm{Mn}^{2+}, 28.7 \%$ of product was produced [52].

In another study by this research group, the combination of this IL with manganese(II) chloride as a co-catalyst also exhibited excellent yield in cellobiose (61) hydrolysis in dilute aqueous sulfuric acid (Scheme 11). The authors found that the highest enhancement in the yield of the product happens at $60^{\circ} \mathrm{C}$. This may be owing to this fact that a weak interaction between manganese(II) chloride and cellobiose generates the co-catalytic effect. The interactions of $\mathrm{MnCl}_{2}$ with -OH groups and other oxygen atoms of cellobiose were confirmed by IR spectroscopy [53].
In another study, 1-(3-sulfopropyl)-3-methyl-1 $H$-imidazolium chloride (63) and 1-(4-sulfobutyl)-3-methyl-1 $H$-imidazolium chloride (66) ILs were used as excellent catalysts and the reaction medium for microwave synthesis of quinoline derivatives 65 from substituted anilines 15 and glycerol (64, Scheme 11). Some advantages of these catalytic systems include: elimination of oxidizing agents, ease of isolation of products, very short reaction times (only $10 \mathrm{~s}$ ), and better yields. The use of glycer$\mathrm{ol}$ as a starting material is another important advantage because it is the main byproduct in the biodiesel industry and the application of renewable feedstocks for the preparation of suitable chemicals and intermediates is of current interest [54].

\section{Synthetic strategies of $\mathrm{SiO}_{2}$ and functionalized $\mathrm{SiO}_{2}$ containing sulfonic acid groups as a diverse class of catalysts and their uses in organic reactions}

Nowadays, nanotechnology utilizing substances in the nanometer scale has attracted increasing attention in many fields including adsorbent, optical devices, water purification, drug delivery, and catalysis. Silica nanoparticles with different structures have extensively investigated due to their simple preparation and diverse industrial applications. In addition, $\mathrm{SiO}_{2}$ nanoparticles with high surface area commonly are the first option for heterogenizing the homogeneous catalysts. These solid supports have

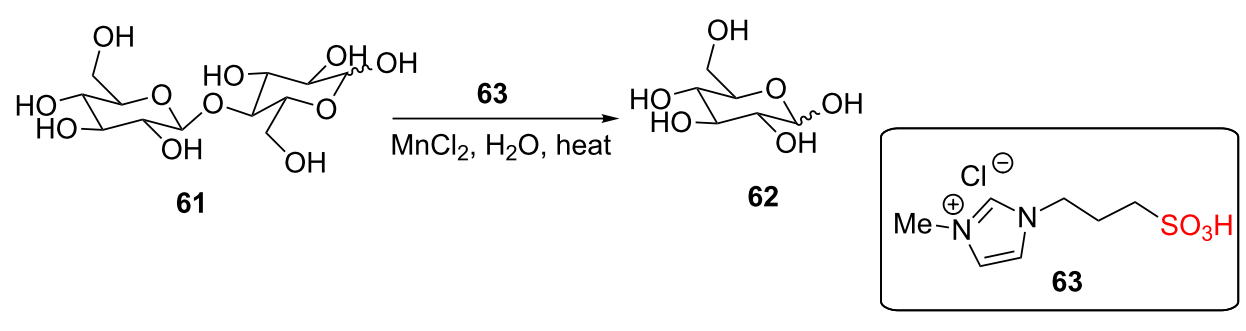

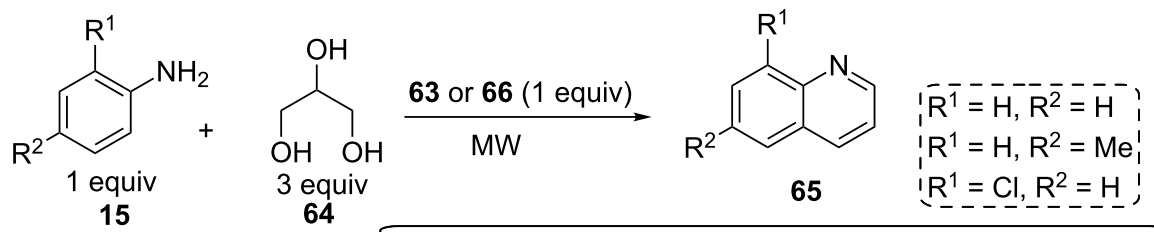
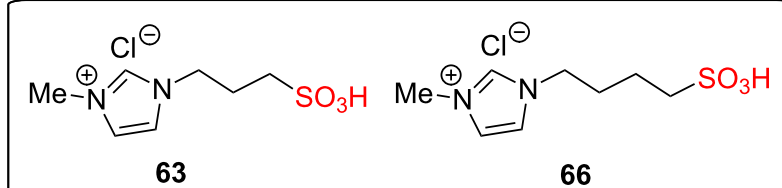

times of reaction in presence of catalysts 63 and $66: 100 \mathrm{~s}$
yields of reaction in presence of catalysts 63 and $66: 67-78 \%$

Scheme 11: The catalytic applications of 1-(1-sulfoalkyl)-3-methylimidazolium chloride acidic ILs for the hydrolysis of cellobiose and the synthesis of quinolones. 
greatly functionalized with various functional groups [55]. In this regard, different functionalized $\mathrm{SiO}_{2}$ containing sulfonic acid groups as novel acid catalysts were employed in different synthetic and multicomponent reactions and some of them were mentioned below.

Moosavi-Zare et al. immobilized 1,4-diazabicyclo[2.2.2]octanesulfonic acid chloride on $\mathrm{SiO}_{2}$ as a nanostructured heterogeneous catalyst. The silica-bonded 1,4-diazabi- cyclo[2.2.2] octanesulfonic acid chloride catalyst 71 was prepared in some steps as demonstrated in Scheme 12. Initially, 69 was formed using the reaction between 1,4-diazabicyclo[2.2.2]octane (67) and (3-chloropropyl)triethoxysilane (68) in refluxing acetone for 12 hours. In the next step, 70 was produced using the reaction between $\mathrm{SiO}_{2}$ and 69 in refluxing toluene for $8 \mathrm{~h}$. Finally, silica supported 1,4-diazabicyclo[2.2.2] octane $\mathbf{7 0}$ was reacted with $\mathrm{ClSO}_{3} \mathrm{H}$ in cold chloroform to give new $-\mathrm{SO}_{3} \mathrm{H}$ functionalized $\mathrm{SiO}_{2}$.

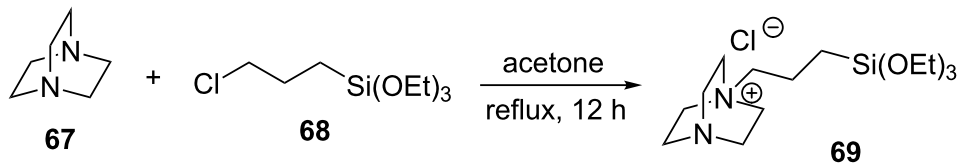

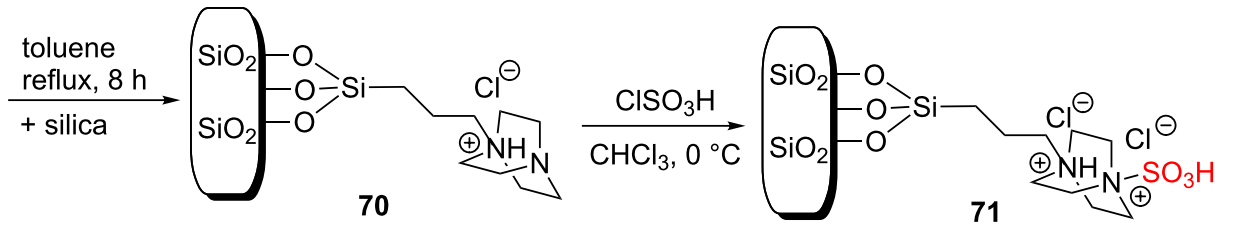

2<smiles>CC(C)(C)O</smiles>

$\mathrm{R}^{1}=4-\mathrm{CIPh}, 2-\mathrm{CIPh}, \mathrm{Ph}, 4-\mathrm{NO}_{2} \mathrm{Ph}, 2-\mathrm{NO}_{2} \mathrm{Ph}, 3-\mathrm{NO}_{2} \mathrm{Ph}$ 4-BrPh, 4-CNPh, 4-MePh, 4-OMePh, 1-ethylPh,

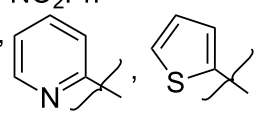<smiles>[R2]C1([R2])CC(=O)CC(=O)C1</smiles>

20<smiles>[R]N1C(=O)CC(=O)N([R])C1=O</smiles>

73
$\mathrm{R}^{2}: \mathrm{H}, \mathrm{Me}$

$\mathrm{R}^{3}: \mathrm{H}, \mathrm{Me}$

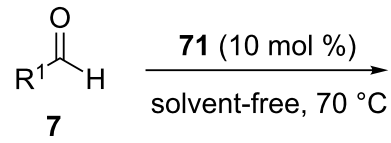

0-18 min

alyst 71: $85-95 \%$<smiles>[X]c1cc([Y])c2c(c1)C(=O)C(=O)N2</smiles>

$$
32 \mathrm{O}
$$<smiles>CC(O)CC1CCCCC1C</smiles>

33

32: 5-iodoisatin, 5-bromoisatin, 5-nitroisatin, 5-methoxyisatin, 5-methylisatin, 5,7-dimethylisatin

times of reaction in presence of catalyst $71: 30-90 \mathrm{~min}$ yields of reaction in presence of catalyst 71 : $87-95 \%$<smiles>[R1]C(c1c(O)c2ccccc2oc1=O)c1c(O)c2ccccc2oc1=O</smiles>

72<smiles></smiles>

74<smiles>[X]c1ccc2c(c1)C1(C(=O)CC([R2])([R2])CC1=C1C(=O)CC([Y5])([R])c3c1c(=O)n([R3])c(=O)n3[R3])C(=O)N2</smiles> 
The authors studied its catalytic behavior in the synthesis of biscoumarin derivatives $\mathbf{7 2}$ using a solvent-free reaction of aryl aldehydes containing electron-donating and electron-withdrawing substitutions 7 with 4-hydroxycoumarin $(\mathbf{3 4 b})$ at $70{ }^{\circ} \mathrm{C}$ within short reaction times. All aromatic aldehydes 7 reacted with 4-hydroxycoumarin (34b) to form bis-coumarins bearing electron-donating groups, electron-withdrawing groups, and halogens $\mathbf{7 2}$ in very short reaction times and in high yields.

In another published article by this research group, silica-supported sulfonated 1,4-diazabicyclo[2.2.2]octane 71 was used for the one-pot tandem Knoevenagel-Michael cyclization reaction between isatin derivatives $\mathbf{3 2}$ or acenaphthenquinone (33), barbituric acid derivatives $\mathbf{7 3}$, and 1,3-dicarbonyl compounds $\mathbf{2 0}$ to afford spiropyran derivatives $\mathbf{7 4}$ and $\mathbf{7 5}$ in aqueous media under reflux conditions (Scheme 12) [56]. The particular features of these protocols are short reaction times, high reaction yields, mild reaction conditions, and diverse desired products. The silica-bonded sulfo-1,4-diazabicyclo[2.2.2] octane chloride 71 was introduced as a highly efficient, reusable, general, and nanostructured catalyst for the synthesis of bis-coumarins $\mathbf{7 2}$ and spiropyrans $\mathbf{7 4}$ and $\mathbf{7 5}$ (Scheme 12) [57].

A silica-bonded sulfoimidazolium chloride $\mathbf{7 6}$ was prepared nearly similar to the previous example. After producing silica supported imidazole derivative, it was sulfonated by the reaction of supported imidazole with $\mathrm{ClSO}_{3} \mathrm{H}$ in cold chloroform to give new $-\mathrm{SO}_{3} \mathrm{H}$ functionalized $\mathrm{SiO}_{2}$. To screen the scope and diversity of this catalyst, several aldehydes containing electrondonating and electron-withdrawing substitutions 7 were reacted with dimedone (5,5-dimethylcyclohexane-1,3-dione, 20) and 2-naphthol (23) to give 12-aryl-8,9,10,12-tetrahydrobenzo[ $a]$ xanthen-11-one derivatives 27 containing electrondonating and electron-withdrawing substitutions at $100{ }^{\circ} \mathrm{C}$ under solvent-free conditions (Scheme 13) [58].
Veisi et al. carried out the synthesis of $2 H$-indazolo[2,1$b$ ]phthalazinetrione derivatives $\mathbf{5 5}$ and triazolo[1,2- $a$ ] indazoletrione derivatives $\mathbf{8 1}$ using solvent-free reactions between aldehydes 7, dimedone (20), and phthalazine (54) or $N$-phenylurazoles $(\mathbf{8 0})$ at $80^{\circ} \mathrm{C}$ in the presence of catalytic amount of a mesoporous SBA-15 silica functionalized with sulfonic acid groups (SBA-15-Ph- $\mathrm{SO}_{3} \mathrm{H}, 79$ ). The reactions proceeded well using $5 \mathrm{~mol} \%$ of the catalyst to form the corresponding products $\mathbf{5 5}$ and $\mathbf{8 1}$ in good to excellent yields under mild reaction conditions.

As a short explanation of the SBA-15-Ph- $\mathrm{SO}_{3} \mathrm{H}$ synthesis, an aqueous solution of Pluronic P123 was added to an aqueous solution of hydrochloric acid. After $2 \mathrm{~h}$, tetraethyl orthosilicate was added and heated to $35^{\circ} \mathrm{C}$ for $24 \mathrm{~h}$. The temperature was fixed at $80^{\circ} \mathrm{C}$ and the mixture was aged for $24 \mathrm{~h}$ without stirring. The resulted material was reacted with dichlorodiphenylsilane in dry toluene under reflux conditions for $12 \mathrm{~h}$ to obtain phenyl-modified SBA-15 as a white solid material. In the next step, all -OH groups on the phenyl-modified SBA-15 77 were protected in dry hexane by the addition of trimethylsilyl chloride. The mixture was refluxed for $8 \mathrm{~h}$ to produce trimethylsilylated phenyl-modified SBA-15 78. This white solid was reacted with $\mathrm{ClSO}_{3} \mathrm{H}$ to get SBA-15 functionalized with phenyl sulfonic acid groups (SBA-15- $\mathrm{Ph}-\mathrm{SO}_{3} \mathrm{H}, 79$, Scheme 14). The SBA-15-Ph- $\mathrm{SO}_{3} \mathrm{H}$ catalyst 79 is a hydrophobic nanoreactor solid acid catalyst that presents a series of advantages, such as recyclability, resistant to leaching in organic and aqueous solutions, and stability to water (and also to air and moisture) [59].

In 2015, Rostamnia and co-workers increased the catalytic activity of SBA-15- $\mathrm{SO}_{3} \mathrm{H}$ through hydrophilic/hydrophobic fluoroalkyl-chained alcohols. One of the major drawbacks of the sulfonated mesoporous silica materials is that they are poisoned with water. To increase the hydrophobicity of them, the authors<smiles>Oc1ccc2ccccc2c1</smiles>

23<smiles>[R]C=O</smiles>

7<smiles>CC1(C)CC(=O)CC(=O)C1</smiles>

20

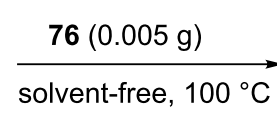<smiles>[R]C1C2=C(CC(C)(C)CC2=O)Oc2ccc3ccccc3c21</smiles>

27

$\mathrm{R}^{1}=\mathrm{X}-\mathrm{Ph}(\mathrm{X}=$ electron-donating groups, electron-withdrawing groups, and halogens)

times of reaction in presence of catalyst $76: 7-27 \mathrm{~min}$ !

yields of reaction in presence of catalyst $76: 83-96 \%$ :

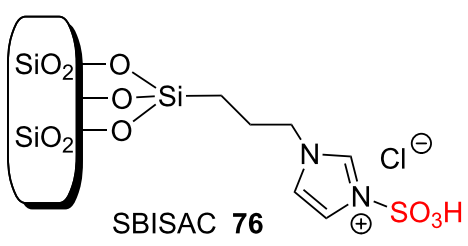

Scheme 13: The catalytic application of a silica-bonded sulfoimidazolium chloride for the synthesis of 12-aryl-8,9,10,12-tetrahydrobenzo[a]xanthen11-ones. 

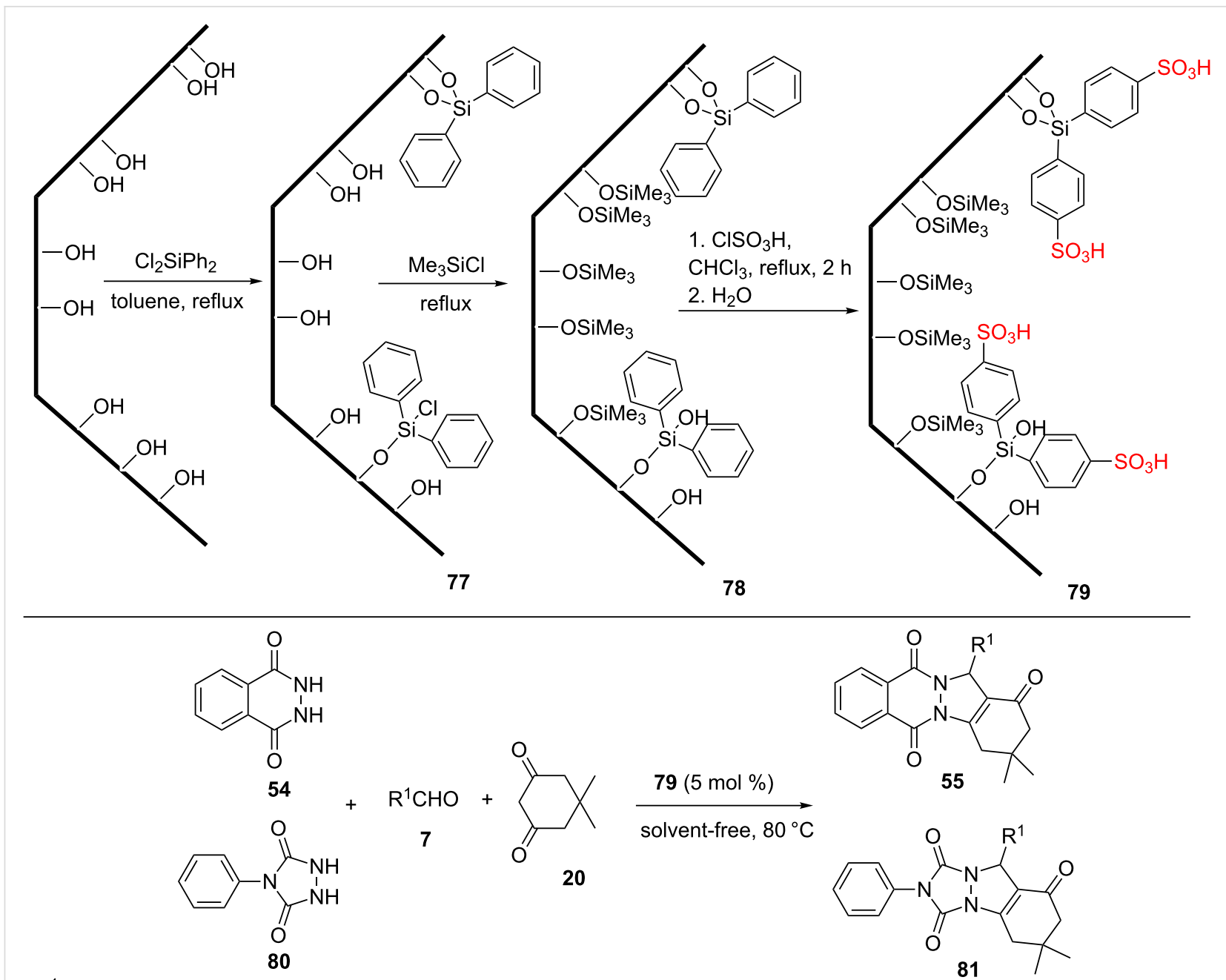

$\mathrm{R}^{1}=\mathrm{Ph}, 4-\mathrm{CIPh}, 4-\mathrm{BrPh}, 4-\mathrm{MeOPh}, 3-\mathrm{NO}_{2} \mathrm{Ph}, 2,4-$ diClPh, 3,4,5-triMeOPh, alyphatic chain

times: 5-50 min

Scheme 14: The synthetic route of the SBA-15- $\mathrm{Ph}-\mathrm{SO}_{3} \mathrm{H}$ and its catalytic applications for the synthesis of $2 \mathrm{H}$-indazolo[2,1-b]phthalazinetriones and triazolo[1,2-a]indazoletriones.

reported some solutions such as confining fluoroalkyl-chain alcohols $\left(\mathrm{R}_{\mathrm{F}} \mathrm{OH}\right)$ inside them. A range of $\mathrm{R}_{\mathrm{F}} \mathrm{OH}$ including trifluoroethanol (TFE), ethanol, hexafluoroisopropanol (HFIP) was explored for tetrasubstituted imidazole synthesis from primary amines, aromatic aldehydes, ammonium acetate, and phenylglyoxal. The TFE-modified SMSM had better behavior than others. To highlight the catalytic activity of the $\mathrm{R}_{\mathrm{F}} \mathrm{OH} /$ $\mathrm{SBA}-15-\mathrm{Pr}-\mathrm{SO}_{3} \mathrm{H}$, the reaction was also carried out with non$\mathrm{R}_{\mathrm{F}} \mathrm{OH}$-functionalized catalyst. The SBA-15- $\mathrm{SO}_{3} \mathrm{H}$ containing fluorinated alcohols had more catalytic activity [60].

In an initiative research, Doustkhah and Rostamnia developed a green catalytic system based on SBA-15 mesoporous silica with sulfamic acid content. This heterogeneous Brønsted solid acid was used as an efficient and reusable catalyst for rapid oxida- tion of a series of aromatic and aliphatic sulfides at room temperature under aqueous medium. The simplicity of the process, chemoselectivity towards sulfoxides, and recyclability at least for eleven runs were the merits of this procedure [61].

Zhou et al. described the immobilizing heteropolyanion-based ionic liquids on mesoporous silica SBA-15. They synthesized intact mesostructures with well-ordered hexagonal arrays of 2D mesoporous channels. $\mathrm{N}$-Triethoxysilylpropylimidazole (82) was produced by the reaction between imidazole (9) and 3-triethoxysilylpropyl chloride (68) in the presence of a base $(\mathrm{NaH})$ in toluene as solvent under a nitrogen atmosphere. Then, triethoxysilylpropylimidazole (82) and 1,3-propane sultone (83) were stirred at $50{ }^{\circ} \mathrm{C}$ for $8 \mathrm{~h}$ under a nitrogen atmosphere to produce 1-(3-sulfonatopropyl)-3-(3-(triethoxysilyl)propyl)-1H- 
imidazol-3-ium (84). A mixture of 1-(3-sulfonatopropyl)-3-(3(triethoxysilyl)propyl)-1 $H$-imidazol-3-ium (84) and dry SBA-15 was refluxed in dry toluene for 24 hours under nitrogen atmosphere to produce sulfonated ionic imidazole on SBA-15 85 Finally, tungstophosphoric acid (HPW) was added to the dispersed sulfonated ionic imidazole on SBA-15 85 in deionized water and stirred at $25{ }^{\circ} \mathrm{C}$ for $12 \mathrm{~h}$ (Scheme 15). The HPW-based ionic liquid immobilized on mesoporous silica SBA-15 86 displayed excellent utility and reusability for alkylation of $o$-xylene $(\mathbf{8 7})$ with styrene $(\mathbf{8 8})$.

Although the homogeneous HPW displayed very high catalytic activity for the alkylation of $o$-xylene with styrene, it cannot be separated from the reaction mixture. The SBA-15 support itself exhibited no activity for the reaction, but $30 \%$ HPW-PMIMPSSBA-15 material produced the highest yield and showed good selectivity. Decreasing and increasing in the amount of HPW on silica decreased the yield of reaction [62].

The silica sulfuric acid (SSA) catalyst was synthesized by the treatment of silica gel with sulfuryl chloride under room temperature stirring. The catalyst was used in the acylation of amines with 1,3-diketones via $\mathrm{C}-\mathrm{C}$ bond cleavage. Various protected aniline derivatives were obtained by the solvent-free reaction of anilines with 1,3 -diketones at $120^{\circ} \mathrm{C}$ or $140{ }^{\circ} \mathrm{C}$ in the presence of 2 equiv of water under 1 atm $\mathrm{O}_{2}$ atmosphere (Scheme 16). The probable reaction pathway for this reaction is shown in Scheme 16. Arylamine 15 attacks the activated carbonyl of acetylacetone $\mathbf{9 0}$ to form enamine intermediate II. In the next step, hydroxyl radicals are produced through activation of molecular oxygen in the presence of SSA. Intermediate III is created via the addition of a hydroxyl radical to enamine II. This intermediate loses hydrogen radical to form intermediate IV. Finally, this intermediate is split by a nucleophilic attack of hydroxyl radicals to afford byproducts (including acetic acid, acetanilide, and formic acid) and desired product. The proposed mechanism was confirmed by EPR spectrum. The SSA catalyst is an inexpensive and reusable solid acid catalyst [63].

\section{Synthetic strategies of carbon-based materials and functionalized carbon-based materials containing sulfonic acid groups as a diverse class of catalysts and their uses in organic reactions}

Carbon-based materials containing sulfonic acid groups [33] have been used as novel, efficient, and reusable catalysts, due to
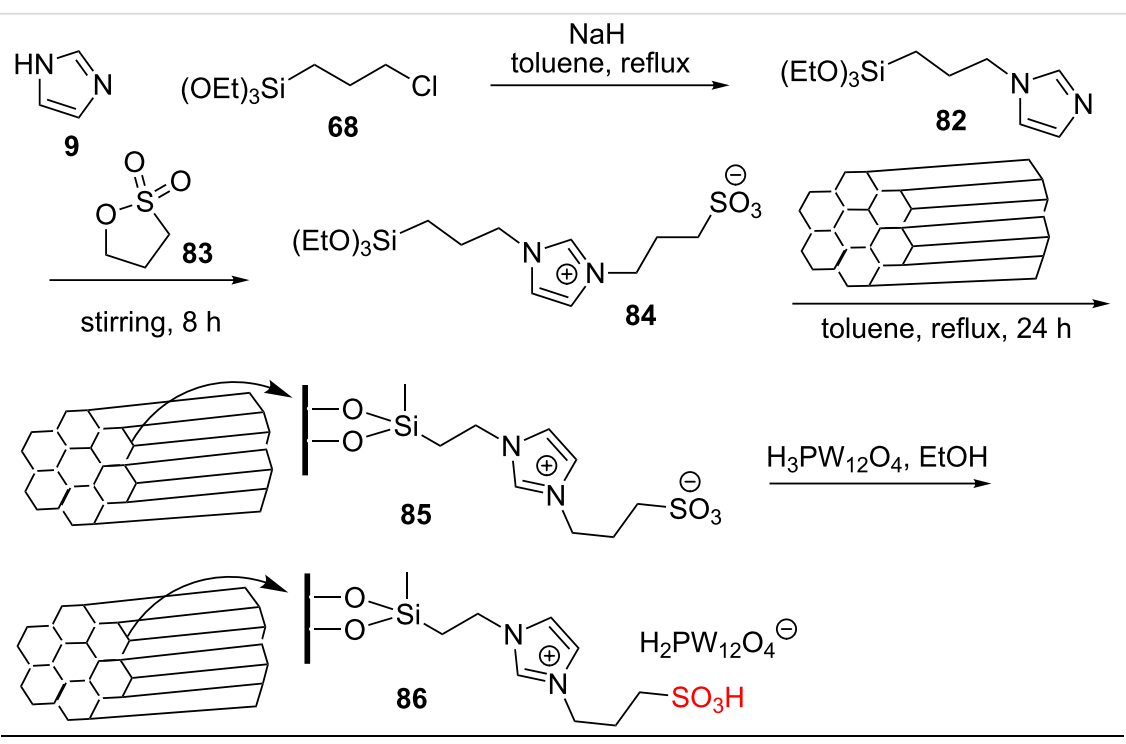

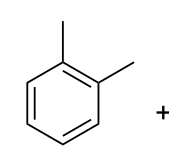

87

$-------$

time: $3 \mathrm{~h}$

yield: $93.9 \%$

Scheme 15: The synthetic route for heteropolyanion-based ionic liquids immobilized on mesoporous silica SBA-15 and its catalytic activity for the alkylation of $o$-xylene with styrene. 


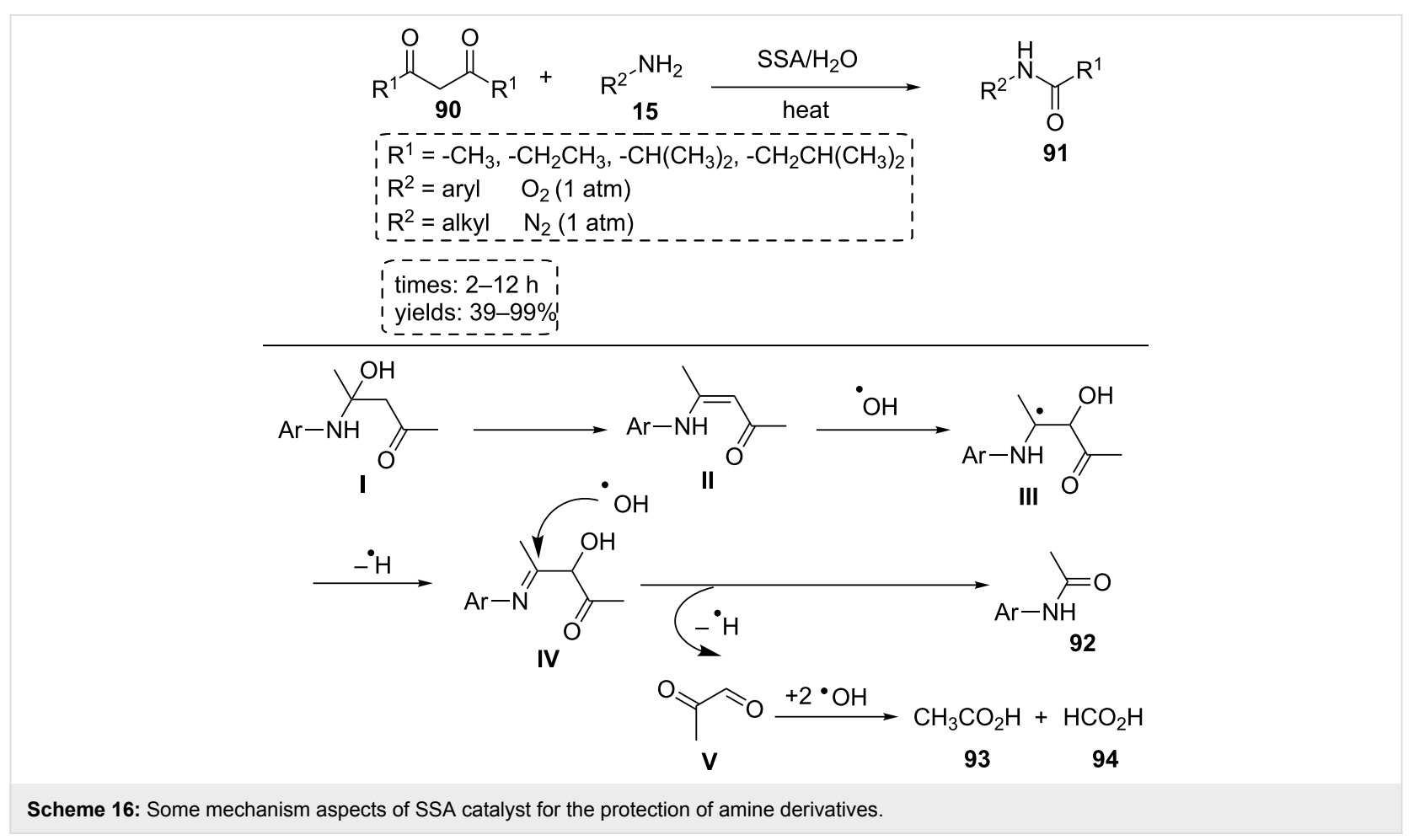

their ability to catalyze different chemical processes in industry and laboratories. There are many reports on the carbon-based materials containing the sulfonic acid group, but the future advances of this field will depend on the better understanding of all aspects of their synthetic routes and catalytic applications [64]. The various properties including tunable porosity, stability, and surface chemistry of the carbon-based materials make the carbon-based materials appropriate for use in many catalytic transformations.

In this regard, different functionalized carbon-based materials containing sulfonic acid groups as novel acid catalysts were employed in different industrial and synthetic reactions which some of them were mentioned below.

Sulfonated multi-walled carbon nanotubes (MWCNT- $\left.\mathrm{SO}_{3} \mathrm{H}\right)$ can be created following the strategy illustrated in Scheme 17. Supported sulfonic acid is generally prepared in several steps: (a) sonication of MWCNTs for $30 \mathrm{~min}$, (b) addition of sonicated MWCNTs to another flask containing $\mathrm{HNO}_{3}$ and $\mathrm{HCl}$ with stirring at $80{ }^{\circ} \mathrm{C}$ for $4 \mathrm{~h}$ to form MWCNTs-COOH material 96, (c) sonication of MWCNTs-COOH for $15 \mathrm{~min}$, (d) addition of $\mathrm{H}_{2} \mathrm{SO}_{4}$ to a set-up at $250-270{ }^{\circ} \mathrm{C}$ for $20 \mathrm{~h}$, (e) after filtration, washing, and drying, MWCNTs- $\mathrm{SO}_{3} \mathrm{H}$ composite 97 was achieved (Scheme 17).

$\mathrm{N}$-Substituted pyrroles 99 were obtained in good to excellent yields (40-92\%) via a simple and green reaction between 2,5 - dimethoxytetrahydrofuran (98) and primary amines $\mathbf{1 5}$ in water media at $80{ }^{\circ} \mathrm{C}$ using MWCNTs- $\mathrm{SO}_{3} \mathrm{H}$ composite 97 as the efficient and heterogeneous catalyst. The reaction was also performed under the same conditions using different catalysts including $\mathrm{Fe}_{3} \mathrm{O}_{4}, \mathrm{CuFe}_{2} \mathrm{O}_{4}, \mathrm{ZnS}$ nanoparticles, $\mathrm{TiO}_{2}$, MWCNTs, MWCNTs $/ \mathrm{H}_{2} \mathrm{SO}_{4}$, MWCNTs-COOH, and $\mathrm{Ph}-\mathrm{SO}_{3} \mathrm{H}$, but the products were not achieved in appropriate yields and times.

The easy preparation of the catalyst, short reaction times, easy handling, low-cost procedure, good to excellent reaction yields, and eco-friendly are some of the advantages of this study. The reusability of the catalyst is a very significant feature. In this case, the catalyst was filtered, washed with chloroform and ethanol, and finally dried at $100{ }^{\circ} \mathrm{C}$ for $24 \mathrm{~h}$. The catalyst was reused for four runs with good results (the yields of products ranged from 40 to $92 \%$ ) [65].

A series of sulfonated polymers covalently grafted on multiwall carbon nanotubes (MWCNTs) composite materials such as poly(1-vinyl-3-sulfo- $1 H$-imidazolium chloride) grafted on MWCNT 100, poly(4-styrenesulfonic acid) grafted on MWCNT 101, and poly(4-vinyl-1-sulfo-pyridinium chloride) grafted on MWCNT 102 (CNT-PVSAIC, CNT-PSSA, and CNT-PVSAPC, respectively) was prepared (Scheme 18). Obtained sulfonated polymer-carbon nanotubes composites (CNT$\left.\mathrm{P}-\mathrm{SO}_{3} \mathrm{H}\right) \mathbf{1 0 0}-\mathbf{1 0 2}$ were described as outstanding catalysts for liquid phase transesterification of triglycerides 103 with methanol. The catalysts were also used for the esterification of oleic 

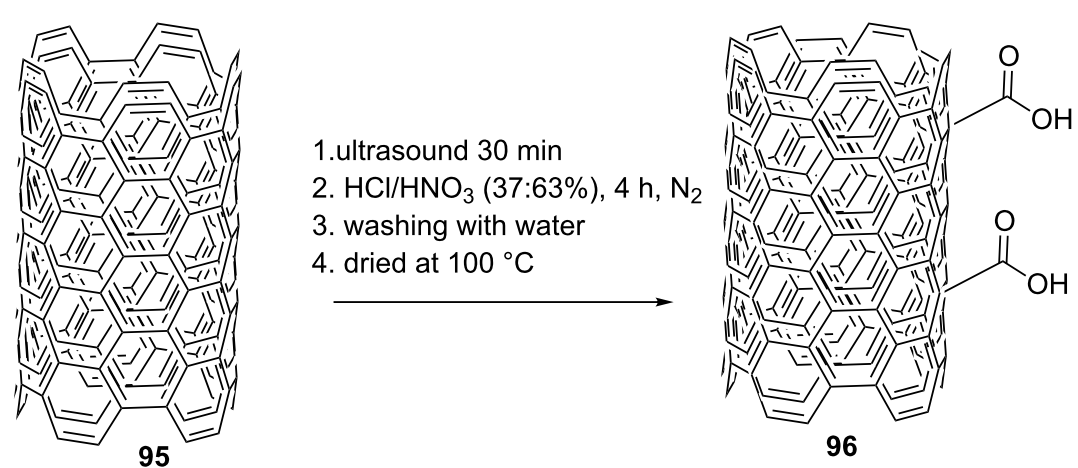

96
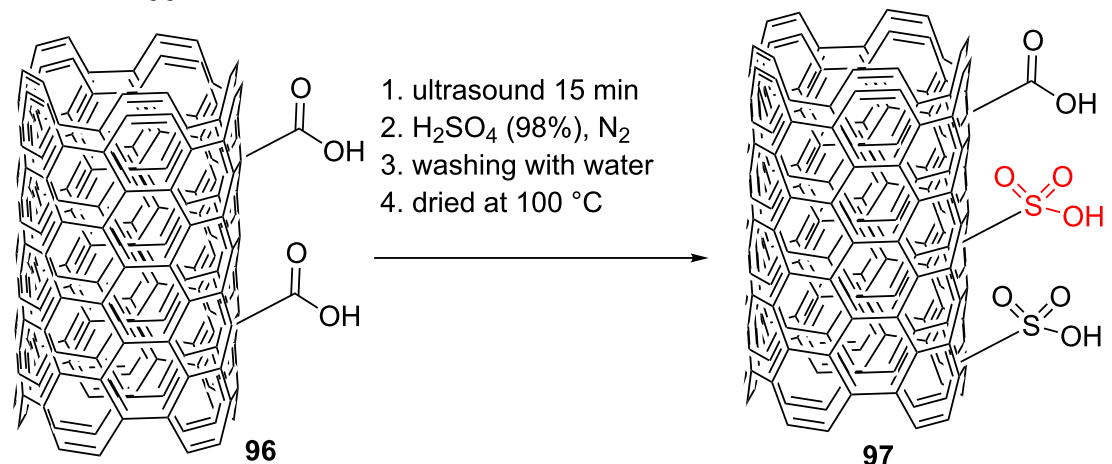

97

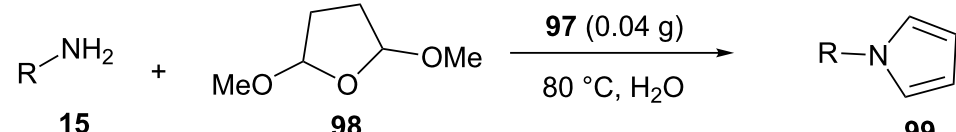

15

98

99

$\mathrm{R}=$ electron-donating groups, electron-withdrawing groups, and halogens

times of the reaction: $10-720$ min'

times of the reaction: $10-720 \mathrm{~min}$
yields of the reaction: $40-92 \%$

yields of the reaction: $40-92 \%$

Scheme 17: The synthetic route for $\mathrm{MWCNT}-\mathrm{SO}_{3} \mathrm{H}$ and its catalytic application for the synthesis of $\mathrm{N}$-substituted pyrrole derivatives

acid (106) with methanol. The important feature of this study is that these reactions are considered as typical model reactions in biodiesel production. To highlight the effect of acid groups, authors investigated the imidazolyl and pyridinyl polymers grafted on MWCTs for the transesterification of triglyceride 103 and low desired product (ranging from 12.3 to $15.1 \%$ ) was obtained under same conditions. This may be related to Brønsted basicity of imidazolyl and pyridinyl groups. In addition to the catalytic role of well-extended $\mathrm{P}-\mathrm{SO}_{3} \mathrm{H}$ coating over the external surface of the CNT, even the mesoporous structure of the support may play a role in catalysis [66].

In the next example, sulfonated multi-walled carbon nanotubes were reported as a catalyst to produce fatty acid ethyl ester (biodiesel production). In this case, triglycerides $\mathbf{1 0 8}$ and ethanol were absorbed through the interaction between the acid sites on MWCNTs and the oxygen atom of substrates. The oxygen of ethanol likely attacks the carbon of the carbonyl group to produce the final product (Scheme 19). It should be noted that the reaction proceeded well in the presence of $3.7 \mathrm{wt} \%$ of the catalyst to produce a high yield of the desired product (overall conversion of $97.8 \%$ ) in ethanol at $150{ }^{\circ} \mathrm{C}$ for $1 \mathrm{~h}[67]$.

The hypercrosslinked supermicroporous polymer (HMP-1, 113) was also designed and prepared by iron(III) chloride catalyzed Friedel-Crafts alkylation of carbazole (111) with $\alpha, \alpha^{\prime}$-dibromo$p$-xylene (112). In the next step, HMP-1 (113) was sulfonated by $\mathrm{Cl}-\mathrm{SO}_{3} \mathrm{H}$ to form $\mathrm{HMP}-1-\mathrm{SO}_{3} \mathrm{H}$ material 114. The $\alpha, \alpha^{\prime}-$ dibromo- $p$-xylene (112) was chosen as a linker because of containing the benzene rings for post-synthetic functionalization. HMP-1 (113) and HMP-1-SO ${ }_{3} \mathrm{H}(\mathbf{1 1 4})$ were confirmed by IR spectroscopy. The peak corresponding to the $\mathrm{C}-\mathrm{Br}$ bond was not detected in the FTIR spectrum of HMP-1. The peaks at $2900 \mathrm{~cm}^{-1}$ and $3400 \mathrm{~cm}^{-1}$ were the evidence of phenylic $\mathrm{C}-\mathrm{H}$ bond and $\mathrm{N}-\mathrm{H}$ stretching of carbazole, respectively. Peaks at $1022 \mathrm{~cm}^{-1}$ and $1039 \mathrm{~cm}^{-1}$ corresponded to additional crosslinking during the sulfonation process. The catalyst was investigated by BET, SEM, TEM, and TGA-DTA, as well. The BET 


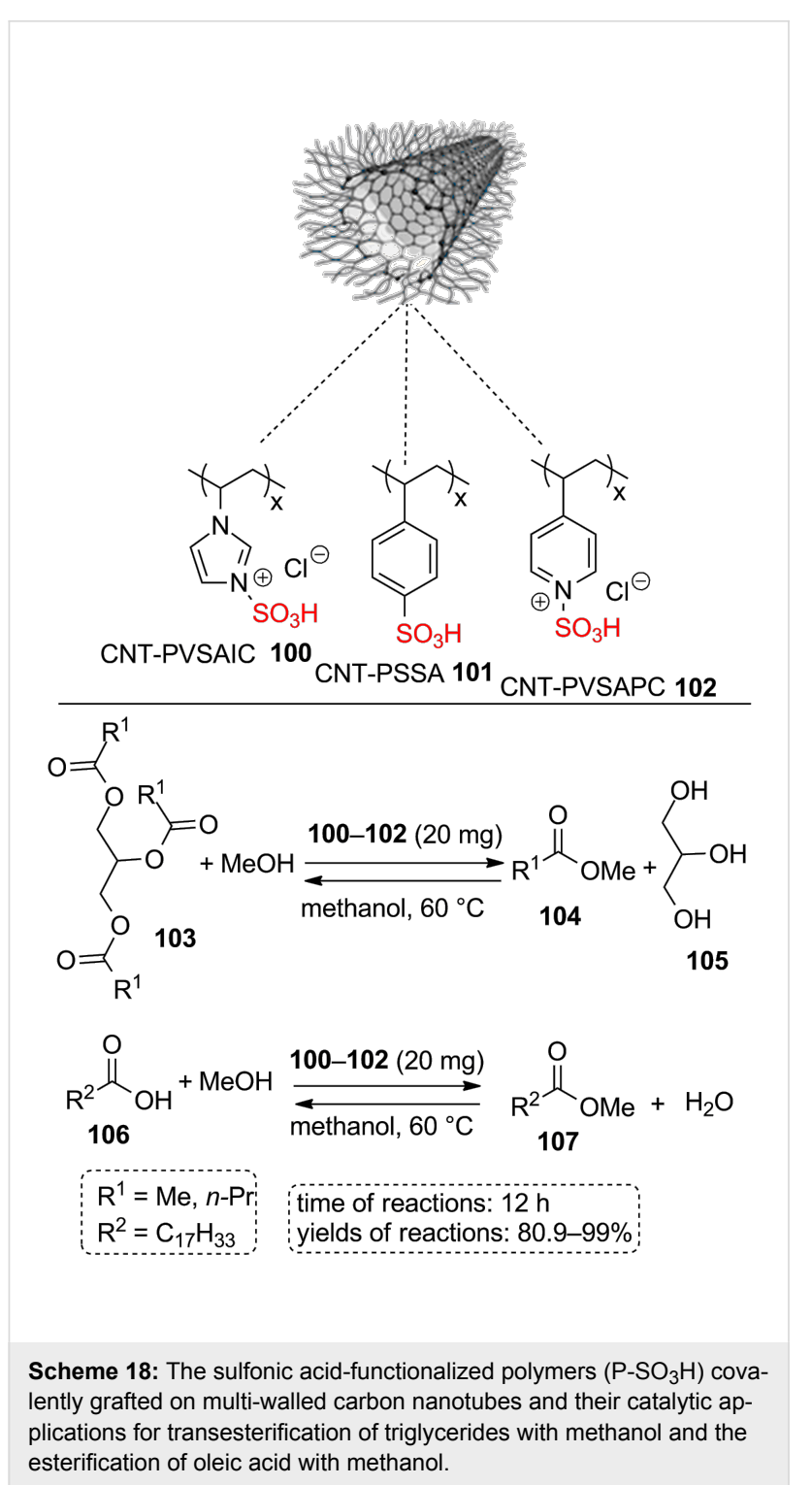

surface area decreased from $913 \mathrm{~m}^{2} \mathrm{~g}^{-1}$ to $346 \mathrm{~m}^{2} \mathrm{~g}^{-1}$ during the sulfonation process. The SEM images of HMP-1 (113) and HMP-1- $\mathrm{SO}_{3} \mathrm{H}$ (114) showed spherical particles. According to the TGA-DTA plot, HMP-1- $\mathrm{SO}_{3} \mathrm{H}$ (114) is less stable than HMP-1 (113).

The resulted catalyst was tested in biodiesel synthesis at room temperature. The esterification of long chain-free fatty acids with methanol was performed well for 10-12 h (Scheme 20). To check the effect of acid groups, HMP-1 (113) was also used as a catalyst for the reaction and low yields of corresponding products were obtained [68].

In another study, a new microporous copolymer synthesized by Friedel-Crafts alkylation of triphenylamine (115) with dibromo-p-xylene 112 was prepared (Scheme 21). After the sulfonation process, the resulted material has been employed as a heterogeneous, reusable, and environmentally benign catalyst in the multicomponent synthesis of polyhydroquinoline derivatives 118 under microwave irradiation. Several substituted aldehydes 7 with dimedone (20), acetoacetate ester 34a, and ammonium acetate in ethanol under microwave irradiation were reacted to produce corresponding products in high yields. In addition to the catalytic role of strong acid strength, the high surface area may play a role in catalysis. The catalyst was reused up to five cycles [69].

Pourmousavi et al. [70] found that sulfonated polynaphthalene 121 synthesized from naphthalene (119) shows high catalytic activities in the one-pot preparation of amidoalkyl naphthols $\mathbf{5 0}$. The sulfonated polynaphthalene can be achieved in two steps: (a) polymerization of naphthalene (119) in nitrobenzene using $\mathrm{FeCl}_{3}$ as reagent (b) sulfonation of polynaphthalene (120) with chlorosulfonic acid in dichloromethane (Scheme 22).

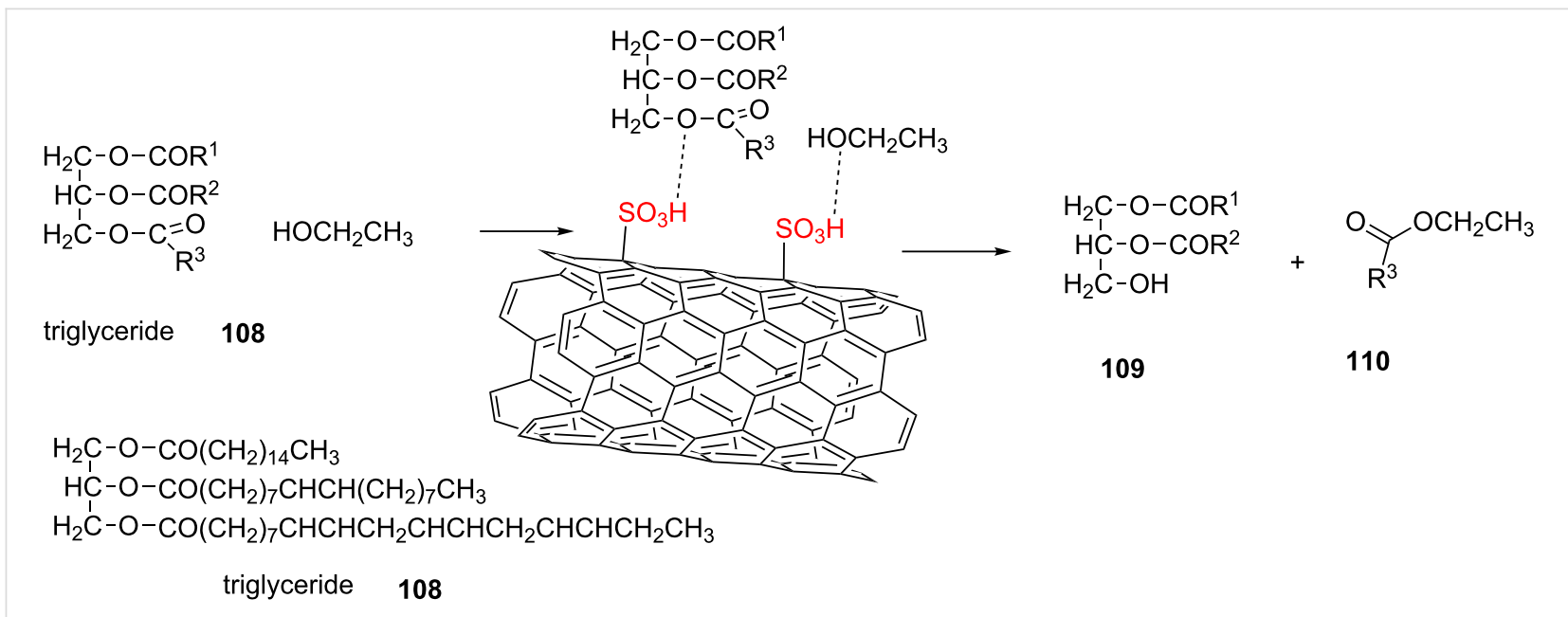

Scheme 19: The transesterification reaction in the presence of S-MWCNTs. 


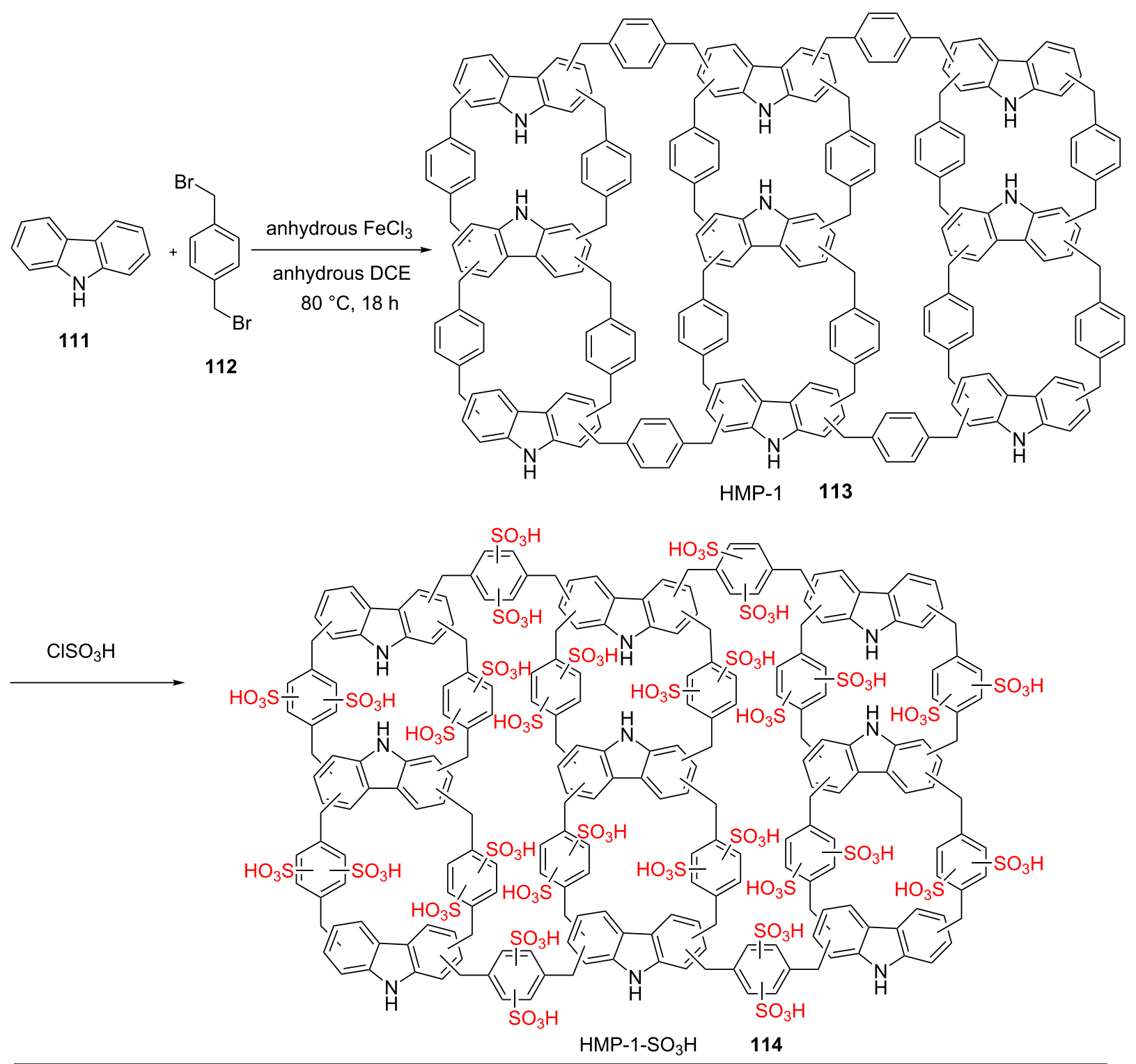

products
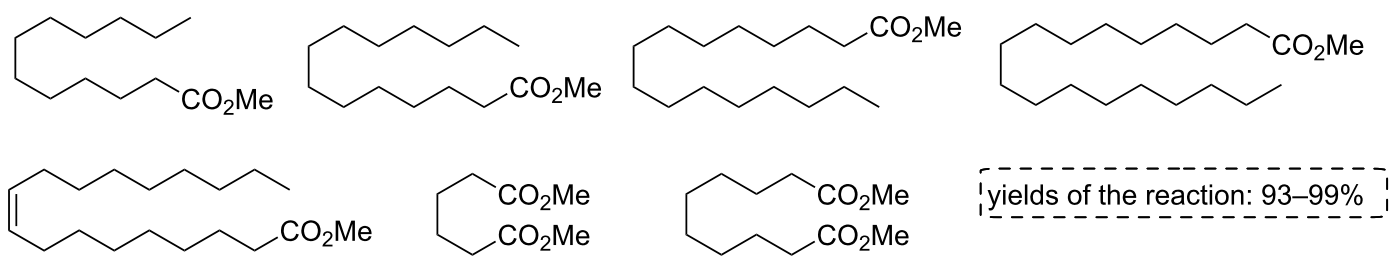

Scheme 20: The synthetic route for the new hypercrosslinked supermicroporous polymer via the Friedel-Crafts alkylation reaction of carbazole with $\alpha, \alpha$-dibromo- $p$-xylene and its catalytic application in biodiesel synthesis.

Amidoalkylnaphthol derivatives $\mathbf{5 0}$ were synthesized using catalyst 121 under thermal solvent-free conditions with good to excellent yields (75-97\%) for short reaction times (11-70 min, Scheme 22). The three-component reaction tolerated one-substi- tuted arylaldehydes including $p-\mathrm{Cl}, o-\mathrm{Cl}, o-\mathrm{NO}_{2}, m-\mathrm{NO}_{2}$, $p$ - $\mathrm{NO}_{2}, o-\mathrm{OMe}, p$-OMe, $p$-OH, and $p$-F as well as two- or three-substituted arylaldehydes including 2,4-dichloro, 2,4-dimethoxy, 3,4-dimethoxy, and 3,4,5-trimethoxy. The cata- 

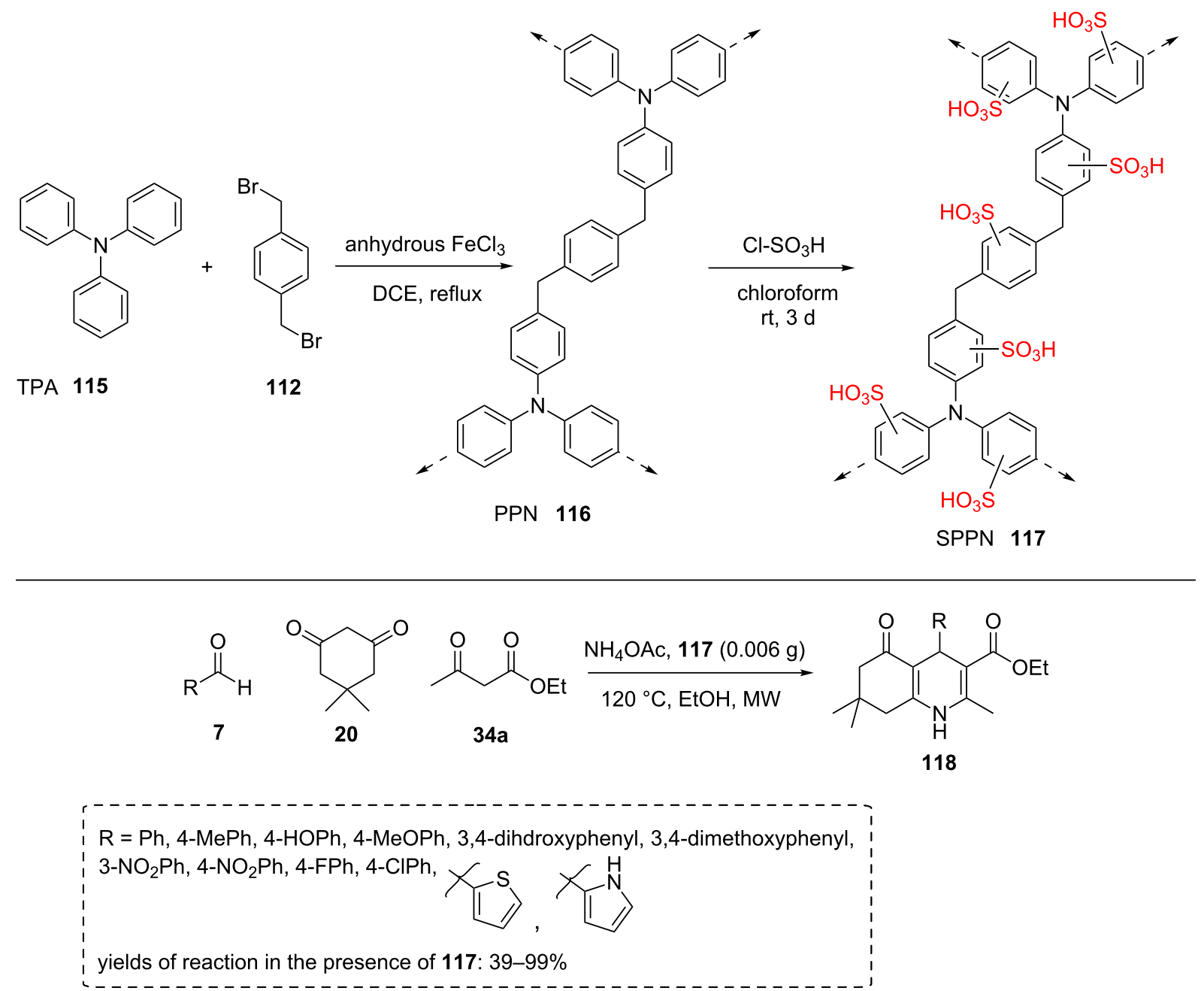

Scheme 21: The synthetic route for a new microporous copolymer via the Friedel-Crafts alkylation reaction of triphenylamine with $\alpha, \alpha-d i b r o m o-p-$ xylene and its catalytic application in multicomponent synthesis.

lyst was used up to four cycles under the optimized conditions [70].

A new strategy was proposed for the synthesis of a novel sulfonated carbon catalyst 127 using the reaction of 5-(hydroxymethyl)furfural (123) with 4-hydroxybenzenesulfonic acid ( $p$-HBSA, 124). As a simple and brief explanation of the sulfonated carbon synthesis, 5-(hydroxymethyl)furfural (123) and $p$-HBSA (124) were dissolved in deionized water to produce a clear brownish red solution. In continuation, the solution was heated at $358 \mathrm{~K}$ and stirred for $2 \mathrm{~h}$. After evaporation of water, a black viscous paste was created. The paste was heated at $303 \mathrm{~K}$ for $1 \mathrm{~h}$ to produce a black solid. The solid was then washed, filtered, and dried at $353 \mathrm{~K}$. To carbonize and sulfonize the solid, it was heated in concentrated sulfuric acid at $443 \mathrm{~K}$ for $12 \mathrm{~h}$. Finally, the carbonized sample was washed and dried at $353 \mathrm{~K}$ overnight. The final material was evaluated as a recoverable catalyst with strong surface acid sites for the etherification of isopentene (128) with methanol (Scheme 23). In this regard, a mixture of isopentene (10 g), methanol (4.57 g), toluene as solvent (35.43 g), and catalyst (0.5 g) was placed in an autoclave equipped with a magnetic stirrer. After sealing and purging with $\mathrm{N}_{2}$, it was heated to $353 \mathrm{~K}$ for $20 \mathrm{~h}$ under stirring. The catalytic activity of the catalyst was studied for three cycles of the reaction and isopentene successively converts to the product in the same yields $(55.2,55.9$ and $54.3 \%$, respectively) [71].

Another research reported for sulfonated carbon material is using low-cost resorcinol (130) and formaldehyde (131) solu- 


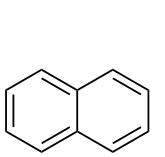

119

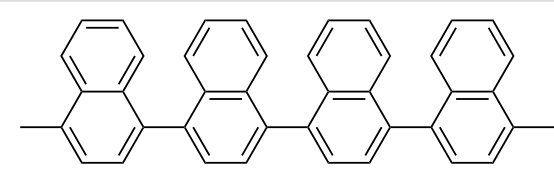

120

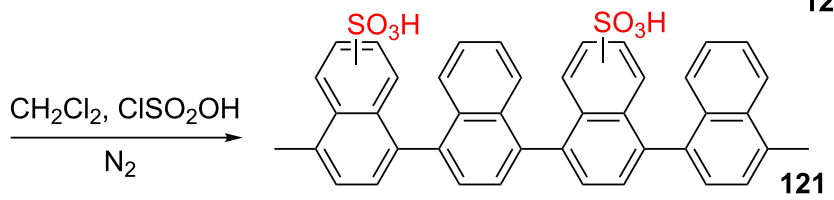<smiles>[X]CC([Y9])C([R])NC(=O)O</smiles>

$\mathrm{R}$ = electron-withdrawing groups, electron-donating groups, and halogens

$\mathrm{X}=\mathrm{Me}, \mathrm{Ph}, \mathrm{CHCl}_{2}, \mathrm{CH}_{2} \mathrm{Cl}, \mathrm{NH}_{2}$

itimes of the reaction: $11-70$ min!

yields of the reaction: $75-97 \%$

Scheme 22: The synthetic route for sulfonated polynaphthalene and its catalytic application for the amidoalkyl naphthol synthesis.

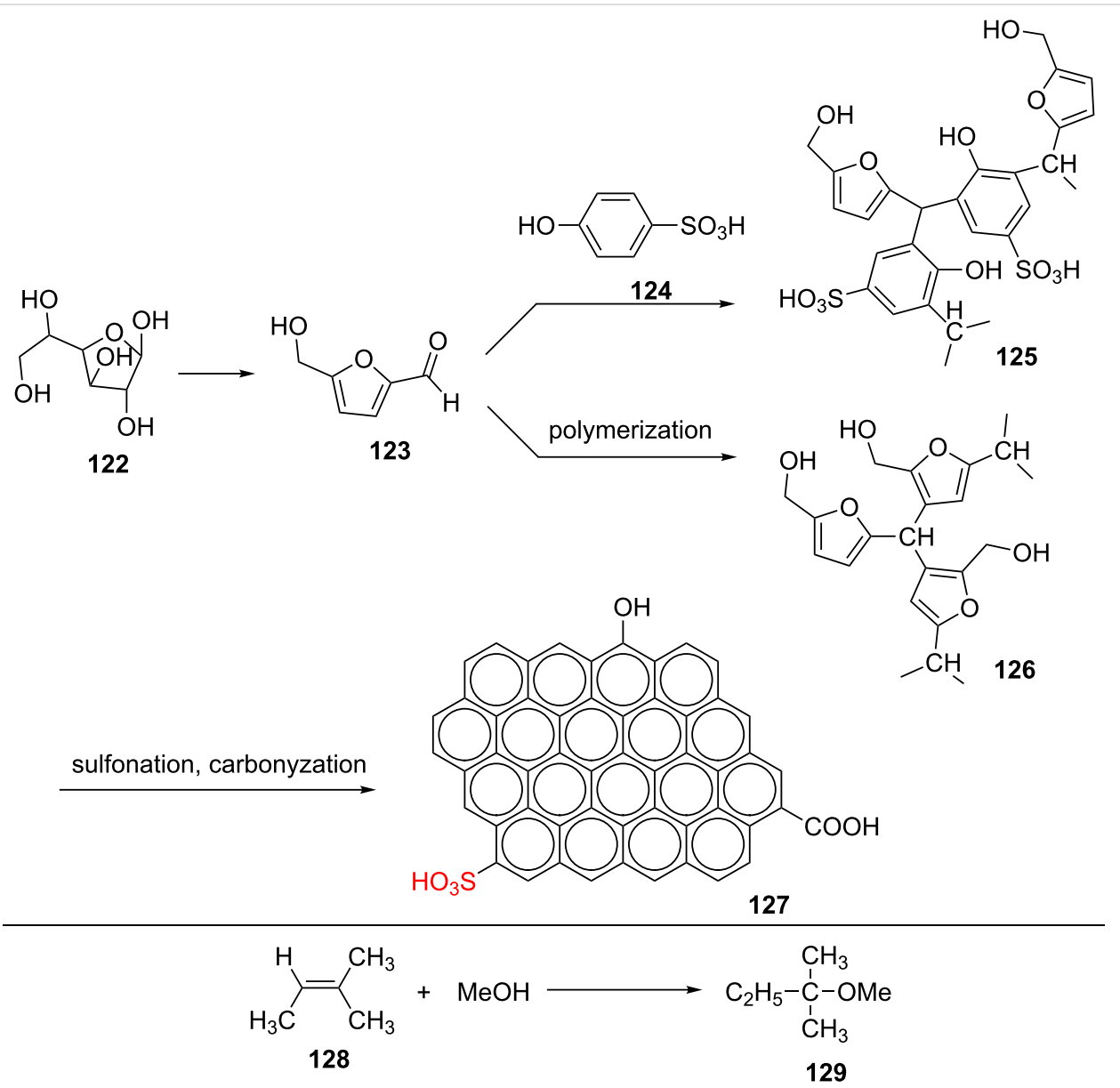

Scheme 23: The synthetic route of the acidic carbon material and its catalytic application in the etherification of isopentene with methanol. 
tion. In this case, resorcinol (130) was added to a stirring solution of aqueous ammonia solution, absolute ethanol, and deionized water. In the next step, formaldehyde (131) solution was added and stirred for $24 \mathrm{~h}$ at $30^{\circ} \mathrm{C}$. The resulted solution was placed in a Teflon-sealed autoclave and heated at $100{ }^{\circ} \mathrm{C}$ for $24 \mathrm{~h}$. Subsequently, the product was centrifuged, washed, and dried. The carbon nanospheres material 132 was obtained by a carbonization process at $400{ }^{\circ} \mathrm{C}$ for $2 \mathrm{~h}$ in an $\mathrm{N}_{2}$ atmosphere [72,73].

This material was dispersed into an aqueous solution containing zinc chloride and stirred for $3 \mathrm{~h}$. After completely evaporation of the aqueous solution, $\mathrm{ZnCl}_{2}$-impregnated $\mathrm{RF}$ resin spheres were obtained. Next, the $\mathrm{ZnCl}_{2}$-impregnated $\mathrm{RF}$ resin spheres were activated at $400{ }^{\circ} \mathrm{C}$ for $2 \mathrm{~h}$ in an $\mathrm{N}_{2}$ atmosphere. Subsequently, the resulted material was washed with $\mathrm{HCl}$ solution and distilled water and then dried under vacuum at $80{ }^{\circ} \mathrm{C}$ for $10 \mathrm{~h}$ to form porous carbon nanospheres material 133 . Finally, the material was sulfonated by concentrated sulfuric acid or $p$-toluenesulfonic acid (Scheme 24) [73].

The catalytic applications of these sulfonated carbon catalysts were investigated in the esterification of oleic acid with methanol (with different ratios of $\mathrm{MeOH} /$ oleic acid) at $70{ }^{\circ} \mathrm{C}$ for $2 \mathrm{~h}$. Theoretically, the esterification process requires one equivalent of oleic acid and one equivalent of methanol to achieve one equivalent of the desired product. But, the esterification is a reversible process, and thus needs the excessive amount of metha- nol to increase the conversion of reactants into products. So high yields were obtained by the $30: 1$ molar ratio of $\mathrm{MeOH} /$ oleic acid.

It is well known that grafting MWCNTs with $-\mathrm{SO}_{3} \mathrm{H}$ functions is very useful for activation of catalysts. On the other hand, the most common technique to sulphonate these materials is through thermal treatment by concentrated sulfuric acid. These procedures are time-consuming and energy intensive, as well. Zou et al. reported an effective strategy for acid-free sulfonation of MWCNTs using the combination of ultrasonication and heating of the mixture of MWCNTs-COOH and $\left(\mathrm{NH}_{4}\right)_{2} \mathrm{SO}_{4}$ solution. After washing the mixture with distilled water, the final product was produced and defined as s-MWCNTs 137 (Scheme 25). In the next step, the type of acid sites on this solid product was identified via pyridine-FTIR spectroscopy. The FTIR spectrum of s-MWCNTs 137 before pyridine adsorption showed no sharp signal, but the FTIR spectrum of s-MWCNTs after pyridine adsorption showed some peaks at 1646, 1626, 1549 and $1476 \mathrm{~cm}^{-1}$. The peaks at 1646, 1626, and $1549 \mathrm{~cm}^{-1}$ could be due to the vibration of pyridinium $\left(\mathrm{PyH}^{+}\right)$species, corresponding to the existence of Brønsted acid sites on the s-MWCNTs 137. The peak at $1476 \mathrm{~cm}^{-1}$ was also labeled to the coordination of electron pair in the nitrogen orbital of pyridine to Brønsted acid sites. No IR signal relating to the Lewis acid sites was detected at $1455 \mathrm{~cm}^{-1}$, as well. Finally, the s-MWCNTs 137 were used in the esterification of palm fatty acid distillate (PFAD) with methanol. The esterification of palm
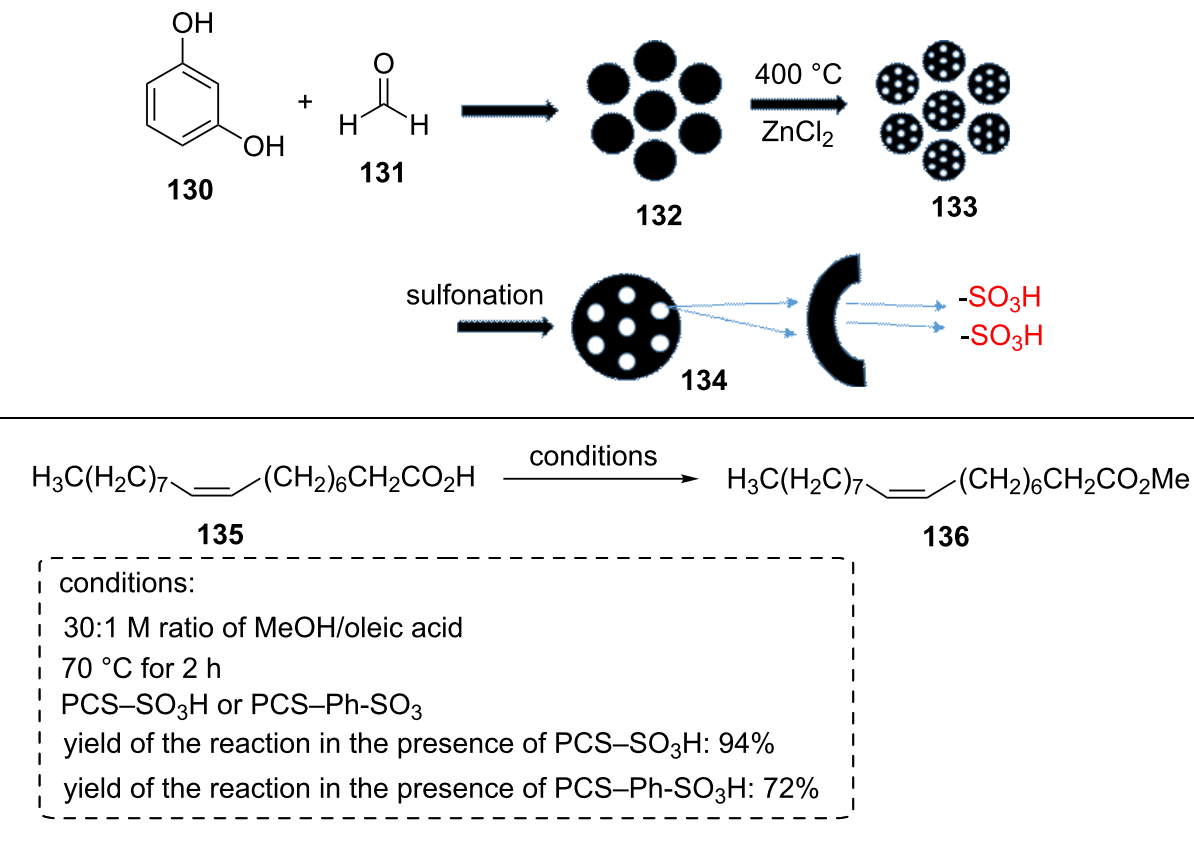
fatty acid with methanol was performed under following conditions: a pressure of $10 \mathrm{bar}$, a reaction temperature of $170{ }^{\circ} \mathrm{C}$, a reaction time of $3 \mathrm{~h}, 20: 1 \mathrm{molar}$ ratio of $\mathrm{MeOH} /$ palm fatty acid distillate, and 2 wt \% of catalyst [74]. An important thing to note is that the s-MWCNTs should be stirred in methanol for $10 \mathrm{~min}$ before use in the reaction. This causes that the tendency of adsorption of PFAD on active sites was decreased and consequently the catalyst will not be deactivated.

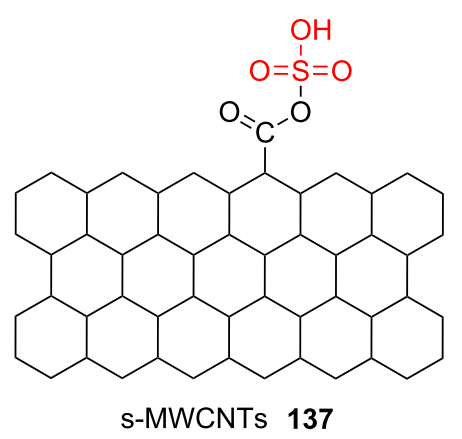

Scheme 25: The sulfonated MWCNTs.

A covalently grafting modified nanoscaled diamond powder with 1,3-propanesultone (Scheme 26) 138 exhibited excellent catalytic activity for esterification under atmospheric conditions and conventional heating [75]. The catalyst showed excellent catalytic activity in the dehydration of D-xylose (139) into furfural (140) as an industrial platform molecule as well as the production of ethylacetate from ethanol and acetic acid [76]. The dehydration of D-xylose (139) into furfural (140) was performed in water-CPME $(1: 3, \mathrm{v} / \mathrm{v})$ and heated in a commercial monowave microwave oven in the presence of $10 \mathrm{wt} \%$ of $\mathbf{1 3 8}$ for $50 \mathrm{~min}$. A maximum furfural yield of $76 \%$ was obtained.

A new sulfonated graphene catalyst GR- $\mathrm{SO}_{3} \mathrm{H}(\mathbf{1 4 5})$ was prepared in some steps. A mixture of graphite powder (141), potassium persulfate, phosphorus pentoxide, and sulfuric acid was heated at $80{ }^{\circ} \mathrm{C}$ for $2 \mathrm{~h}$. The resulted solid was filtered and washed with water, methanol, and ether. Then, the obtained black paste was dried. After mixing the resulting material with sulfuric acid at $0{ }^{\circ} \mathrm{C}$, potassium permanganate was added and stirred at $35{ }^{\circ} \mathrm{C}$ for $2 \mathrm{~h}$. In the next step, the reaction mixture was cooled to $0{ }^{\circ} \mathrm{C}$. Hydrogen peroxide (30\%) in deionized water was added to the reaction mixture. The solid was gathered by centrifugation, washed with deionized water, methanol, and ether, and then dried at $40{ }^{\circ} \mathrm{C}$ under vacuum. The resulting brown solid material was named as graphene oxide (GO, 142). In continuation, a solution of $5 \%$ sodium carbonate was added to the sonicated GO (142) in deionized water so that the $\mathrm{pH}$ was increased up to $9-10.64 \%$ hydrazine hydrate was added as

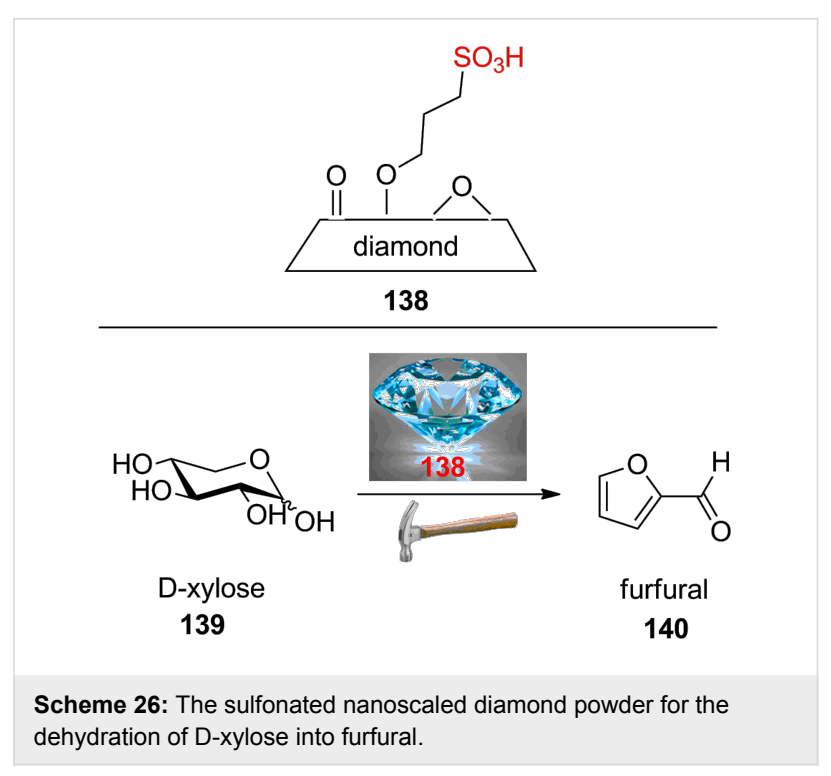

well. Then, the reaction mixture was heated to reflux for $24 \mathrm{~h}$. After cooling down to room temperature, the solution was filtered, washed with $1 \mathrm{~N} \mathrm{HCl}$ and acetone, and then dried. The resulted material was named as graphene $(\mathrm{GR}, \mathbf{1 4 3})$. In order to sulfonate the GR (143), sodium nitrite and sulfanilic acid (144) were added to a sonicated solution of GR (143). Finally, the solution was filtered, washed with $1 \mathrm{~N} \mathrm{HCl}$ and acetone, and dried to produce GR-SO $\mathrm{S}_{3} \mathrm{H}(\mathbf{1 4 5}$, Scheme 27). The effect of different parameters including reaction temperature, catalyst loading, reaction time, and methanol-to-oil molar ratio was investigated for the transesterification of palm oil with methanol into biodiesel. The results showed that the reaction proceeded well by the 20:1 molar ratio of $\mathrm{MeOH} /$ oil in the presence of $10 \mathrm{wt} \%$ catalyst at $100{ }^{\circ} \mathrm{C}$ for $14 \mathrm{~h}$.

The progression of this reaction was studied by ${ }^{1} \mathrm{H}$ NMR in $\mathrm{CDCl}_{3}$. The ${ }^{1} \mathrm{H}$ NMR spectrum of palm oil exhibited some peaks at 4.10-4.32 and 5.31-5.35 ppm for the glycerol scaffold and olefinic protons, respectively. Biodiesel formation was approved through the invisibility of the protons of the glycerol scaffold and appearance of a single peak at $3.63 \mathrm{ppm}$ related to the methyl esters of fatty acids. The catalyst exhibited excellent catalytic activity and reusability for the reaction. The heterogeneous GR-SO ${ }_{3} \mathrm{H}$ (145) displayed a high thermal robustness, as well [77].

\section{Conclusion}

A comprehensive and systematic overview was presented of recent researches that focused on the design, synthesis, and catalytic applications of sulfonated organic materials, sulfonated silica materials, and sulfonated carbon materials as novel catalysts with several features. The efforts to design and preparation of different type of sulfonated catalysts not only focus on 

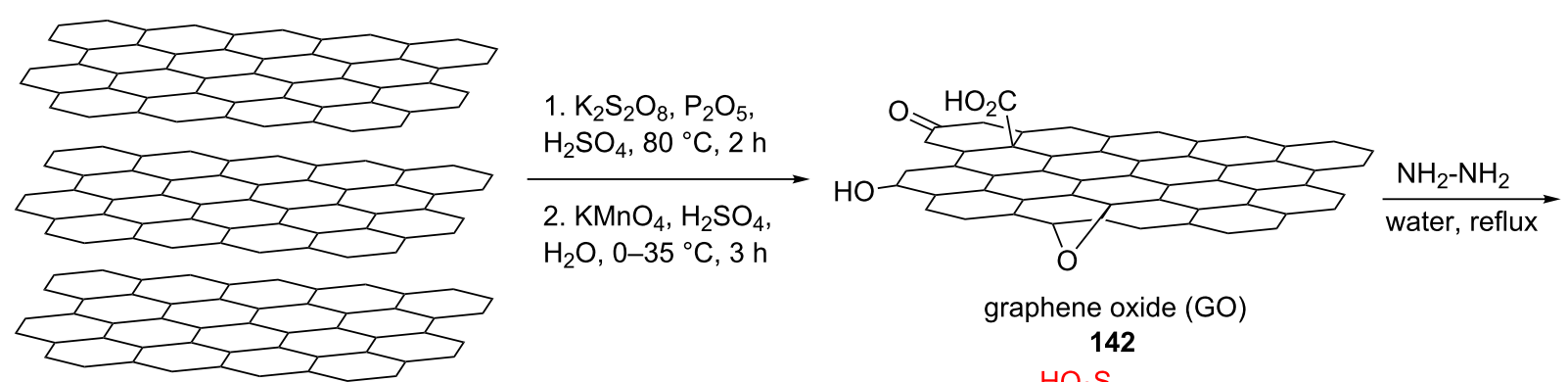

$\mathrm{H}_{2} \mathrm{O}, 0-35^{\circ} \mathrm{C}, 3 \mathrm{~h}$

graphite

141

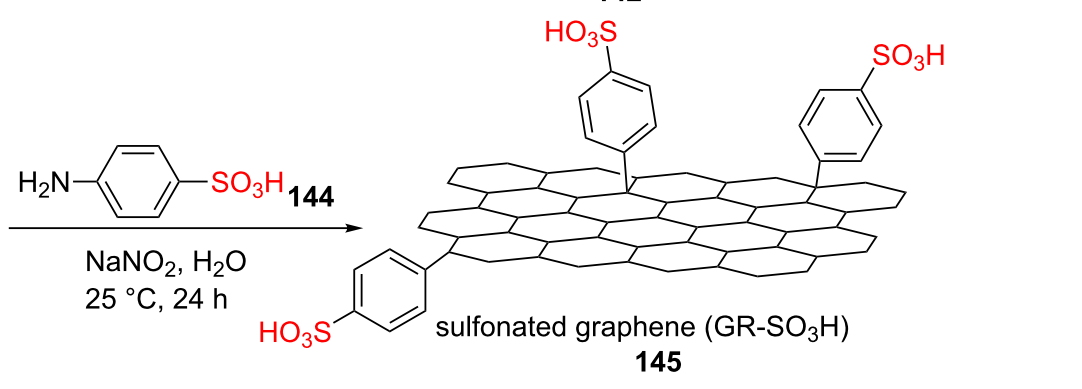

palm oil $\stackrel{\text { conditions }}{\longrightarrow}$ fatty acid methyl esters (FAMEs)

conditions:

10 wt $\%$ catalyst $145, \mathrm{MeOH} /$ oil $20: 1,14 \mathrm{~h}$, and $100^{\circ} \mathrm{C}$

Scheme 27: The synthetic route and catalytic application of the GR-SO${ }_{3} \mathrm{H}$.

the laboratory scale but also on an industrial scale. Researchers are trying to reduce costs of catalyst preparation and regeneration. We believe this review article is valuable for the future design of highly active acidic catalysts.

\section{References}

1. Wilson, K.; Clark, J. H. Pure Appl. Chem. 2000, 72, 1313-1319. doi:10.1351/pac200072071313

2. Lee, A. F.; Wilson, K. Catal. Today 2015, 242, 3-18. doi:10.1016/j.cattod.2014.03.072

3. Steffen, W.; Hughes, L. The Critical Decade 2013: Climate change science, risks and response 2013.; .

4. Shen, F.; Guo, T.; Bai, C.; Qiu, M.; Qi, X. Fuel Process. Technol. 2018, 169, 244-247. doi:10.1016/j.fuproc.2017.10.015

5. Kundu, S. K.; Bhaumik, A. ACS Sustainable Chem. Eng. 2015, 3, 1715-1723. doi:10.1021/acssuschemeng.5b00238

6. De, S.; Dutta, S.; Saha, B. Catal. Sci. Technol. 2016, 6, 7364-7385. doi:10.1039/C6CY01370H

7. Gernon, M.; Wu, M.; Buszta, T.; Janney, P. Green Chem. 1999, 1, 127-140. doi:10.1039/A900157C

8. Naeimi, H.; Raeisi, A.; Moradian, M. Arabian J. Chem. 2017, 10, S2723-S2728. doi:10.1016/j.arabjc.2013.10.017

9. Kulkarni, P.; Wagh, P.; Zubaidha, P. Chem. J. (Nottingham, U. K.) 2012, 2, 106-110.

10. Sharghi, H.; Aberi, M.; Khataminejad, M.; Shiri, P. Beilstein J. Org. Chem. 2017, 13, 1977-1981. doi:10.3762/bjoc.13.193

11. Sajadikhah, S. S.; Maghsoodlou, M. T.; Hazeri, N.; Habibi-Khorassani, S. M.; Shams-Najafi, S. Monatsh. Chem. 2012, 143, 939-945. doi:10.1007/s00706-011-0671-7
12. Sharghi, H.; Jokar, M. Synth. Commun. 2009, 39, 958-979. doi:10.1080/00397910802444258

13. Sharghi, H.; Sarvari, M. H. Tetrahedron 2003, 59, 3627-3633. doi:10.1016/S0040-4020(03)00518-0

14. Sharghi, H.; Kaboudin, B. J. Chem. Res., Synop. 1998, 628-629. doi:10.1039/A800158H

15. Sharghi, H.; Sarvari, M. H. J. Chem. Res. 2001, 10, 446-449. doi:10.3184/030823401103168424

16. Sharghi, H.; Jokar, M. Heterocycles 2007, 71, 2721-2733. doi:10.1016/S0385-5414(07)81208-1

17. Su, F.; Guo, Y. Green Chem. 2014, 16, 2934-2957. doi:10.1039/C3GC42333F

18. Mansir, N.; Taufiq-Yap, Y. H.; Rashid, U.; Lokman, I. M. Energy Convers. Manage. 2017, 141, 171-182. doi:10.1016/j.enconman.2016.07.037

19. Xie, W.; Zhang, C. Food Chem. 2016, 211, 74-82. doi:10.1016/j.foodchem.2016.05.025

20. Thomas, J. M. Proc. R. Soc. London, Ser. A 2012, 468, 1884-1903. doi:10.1098/rspa.2012.0196

21. Vahdat, S. M.; Khaksar, S.; Akbari, M.; Baghery, S. Arabian J. Chem. 2014, in press. doi:10.1016/j.arabjc.2014.10.026

22. Mohammadi Ziarani, G.; Lashgari, N.; Badiei, A. J. Mol. Catal. A: Chem. 2015, 397, 166-191. doi:10.1016/j.molcata.2014.10.009

23. Gholamzadeh, P.; Mohammadi Ziarani, G.; Lashgari, N.; Badiei, A.; Asadiatouei, P. J. Mol. Catal. A: Chem. 2014, 391, 208-222. doi:10.1016/j.molcata.2014.04.025

24. Yadav, G. D.; Nair, J. J. Microporous Mesoporous Mater. 1999, 33, 1-48. doi:10.1016/S1387-1811(99)00147-X 
25. Wang, Y.; Wang, D.; Tan, M.; Jiang, B.; Zheng, J.; Tsubaki, N.; Wu, M. ACS Appl. Mater. Interfaces 2015, 7, 26767-26775.

doi:10.1021/acsami.5b08797

26. Zolfigol, M. A.; Navazeni, M.; Yarie, M.; Ayazi-Nasrabadi, R. Can. J. Chem. 2017, 95, 1248-1252. doi:10.1139/cjc-2017-0232

27. Genies, C.; Mercier, R.; Sillion, B.; Cornet, N.; Gebel, G.; Pineri, M. Polymer 2001, 42, 359-373. doi:10.1016/S0032-3861(00)00384-0

28. Wang, Y.; Huang, J.; Xia, X.; Peng, X. J. Saudi Chem. Soc. 2018, 22, 129-135. doi:10.1016/j.jscs.2016.01.006

29. Saikia, M.; Saikia, L. RSC Adv. 2016, 6, 15846-15853. doi:10.1039/C5RA28135K

30. Sharghi, H.; Aboonajmi, J.; Aberi, M.; Shiri, P. J. Iran. Chem. Soc. 2018, 15, 1107-1118. doi:10.1007/s13738-018-1308-0

31. Lokman, I. M.; Rashid, U.; Taufiq-Yap, Y. H. Arabian J. Chem. 2016, 9, 179-189. doi:10.1016/j.arabjc.2015.06.034

32. Sharghi, H.; Asemani, O. Synth. Commun. 2009, 39, 860-867. doi:10.1080/00397910802431214

33. Sharghi, H.; ShahsavariFard, Z. Helv. Chim. Acta 2005, 88, 42-52. doi:10.1002/hlca.200490295

34. Goli-Jolodar, O.; Shirini, F.; Seddighi, M. RSC Adv. 2016, 6, 26026-26037. doi:10.1039/C6RA04148E

35. Wasserscheid, P.; Welton, T. Ionic liquids in synthesis; John Wiley \& Sons, 2008.

36. Dhakshinamoorthy, A.; Asiri, A. M.; Alvaro, M.; Garcia, H. Green Chem. 2018, 20, 86-107. doi:10.1039/C7GC02260C

37. Welton, T. Chem. Rev. 1999, 99, 2071-2084. doi:10.1021/cr980032t

38. Gogoi, P.; Dutta, A. K.; Sarma, P.; Borah, R. Appl. Catal., A 2015, 492, 133-139. doi:10.1016/j.apcata.2014.12.013

39. Saikia, S.; Gogoi, P.; Dutta, A. K.; Sarma, P.; Borah, R. J. Mol. Catal. A: Chem. 2016, 416, 63-72. doi:10.1016/j.molcata.2016.02.007

40. Dutta, A. K.; Gogoi, P.; Borah, R. RSC Adv. 2014, 4, 41287-41291. doi:10.1039/C4RA07323A

41. Shirini, F.; Abedini, M.; Seddighi, M.; Jolodar, O. G.; Safarpoor, M.; Langroodi, N.; Zamani, S. RSC Adv. 2014, 4, 63526-63532. doi:10.1039/C4RA12361A

42. Shirini, F.; Khaligh, N. G.; Akbari-Dadamahaleh, S. J. Mol. Catal. A: Chem. 2012, 365, 15-23. doi:10.1016/j.molcata.2012.08.002

43. Mohammadi, K.; Shirini, F.; Yahyazadeh, A. RSC Adv. 2015, 5, 23586-23590. doi:10.1039/C5RA02198G

44. Shirini, F.; Yahyazadeh, A.; Mohammadi, K. Chin. Chem. Lett. 2014, 25, 341-347. doi:10.1016/j.cclet.2013.11.016

45. Goli-Jolodar, O.; Shirini, F.; Seddighi, M. Dyes Pigm. 2016, 133, 292-303. doi:10.1016/j.dyepig.2016.06.001

46. Dutta, A. K.; Gogoi, P.; Saikia, S.; Borah, R. J. Mol. Liq. 2017, 225, 585-591. doi:10.1016/j.molliq.2016.11.112

47. Khazaei, A.; Moosavi-Zare, A. R.; Firoozmand, S.; Khodadadian, M. R. Appl. Organomet. Chem. 2018, 32, e4058. doi:10.1002/aoc.4058

48. Tayebee, R.; Jomei, M.; Maleki, B.; Razi, M. K.; Veisi, H.; Bakherad, M. J. Mol. Liq. 2015, 206, 119-228. doi:10.1016/j.molliq.2015.02.021

49. Khaligh, N. G.; Mihankhah, T.; Johan, M. R.; Ching, J. J. J. Mol. Liq. 2018, 259, 260-273. doi:10.1016/j.molliq.2018.03.044

50. Amarasekara, A. S.; Owereh, O. S. Ind. Eng. Chem. Res. 2009, 48, 10152-10155. doi:10.1021/ie901047u

51. Amarasekara, A. S.; Wiredu, B. Ind. Eng. Chem. Res. 2011, 50, 12276-12280. doi:10.1021/ie200938h

52. Wiredu, B.; Amarasekara, A. S. Catal. Commun. 2015, 70, 82-85. doi:10.1016/j.catcom.2015.08.004
53. Amarasekara, A. S.; Wiredu, B. Catal. Commun. 2016, 81, 41-44. doi:10.1016/j.catcom.2016.04.005

54. Amarasekara, A. S.; Hasan, M. A. Tetrahedron Lett. 2014, 55 , 3319-3321. doi:10.1016/j.tetlet.2014.04.047

55. Sharghi, H.; Shiri, P.; Aberi, M. Catal. Lett. 2017, 147, 2844-2862. doi:10.1007/s10562-017-2173-7

56. Moosavi-Zare, A. R.; Zolfigol, M. A.; Noroozizadeh, E.; Salehi-Moratab, R.; Zarei, M. J. Mol. Catal. A: Chem. 2016, 420, 246-253. doi:10.1016/j.molcata.2016.04.021

57. Noroozizadeh, E.; Moosavi-Zare, A. R.; Zolfigol, M. A.; Zare, A.; Zarei, M. Can. J. Chem. 2017, 95, 16-21. doi:10.1139/cjc-2016-0258

58. Moosavi-Zare, A. R.; Zolfigol, M. A.; Zarei, M.; Zare, A.; Khakyzadeh, V. J. Mol. Liq. 2015, 211, 373-380. doi:10.1016/j.molliq.2015.07.049

59. Veisi, H.; Sedrpoushan, A.; Faraji, A. R.; Heydari, M.; Hemmati, S.; Fatahi, B. RSC Adv. 2015, 5, 68523-68530. doi:10.1039/C5RA04949K

60. Rostamnia, S.; Doustkhah, E. Synlett 2015, 26, 1345-1347. doi:10.1055/s-0034-1380683

61. Doustkhah, E.; Rostamnia, S. Mater. Chem. Phys. 2016, 177, 229-235. doi:10.1016/j.matchemphys.2016.04.023

62. Sheng, X.; Zhou, Y.; Yang, Y.; Zhang, Y.; Zhang, Z.; Zhou, S.; Fua, X.; Zhao, S. RSC Adv. 2014, 4, 30697-30703. doi:10.1039/C4RA03531C

63. Guo, R.; Zhu, C.; Sheng, Z.; Li, Y.; Yin, W.; Chu, C. Tetrahedron Lett. 2015, 56, 6223-6226. doi:10.1016/j.tetlet.2015.09.094

64. Rodríguez-reinoso, F. Carbon 1998, 36, 159-175. doi:10.1016/S0008-6223(97)00173-5

65. Naeimi, H.; Dadaei, M. RSC Adv. 2015, 5, 76221-76228. doi:10.1039/C5RA12185J

66. Liu, H.; Chen, J.; Chen, L.; Xu, Y.; Guo, X.; Fang, D. ACS Sustainable Chem. Eng. 2016, 4, 3140-3150. doi:10.1021/acssuschemeng.6b00156

67. Guan, Q.; Li, Y.; Chen, Y.; Shi, Y.; Gu, J.; Li, B.; Miao, R.; Chen, Q.; Ning, P. RSC Adv. 2017, 7, 7250-7258. doi:10.1039/C6RA28067F

68. Bhunia, S.; Banerjee, B.; Bhaumik, A. Chem. Commun. 2015, 51, 5020-5023. doi:10.1039/C4CC09872B

69. Mondal, S.; Patra, B. C.; Bhaumik, A. ChemCatChem 2017, 9, 1469-1475. doi:10.1002/cctc.201601409

70. Pourmousavi, S. A.; Moghimi, P.; Ghorbani, F.; Zamani, M. J. Mol. Struct. 2017, 1144, 87-102. doi:10.1016/j.molstruc.2017.05.010

71. Zhao, Y.; Wang, H.; Zhao, Y.; Shen, J. Catal. Commun. 2010, 11, 824-828. doi:10.1016/j.catcom.2010.03.001

72. Liu, J.; Qiao, S. Z.; Liu, H.; Chen, J.; Orpe, A.; Zhao, D.; Lu, G. Q. Angew. Chem. 2011, 123, 6069-6073. doi:10.1002/ange.201102011

73. Chang, B.; Guo, Y.; Yin, H.; Zhang, S.; Yang, B. J. Solid State Chem. 2015, 221, 384-390. doi:10.1016/j.jssc.2014.10.029

74. Shuit, S. H.; Ng, E. P.; Tan, S. H. J. Taiwan Inst. Chem. Eng. 2015, 52, 100-108. doi:10.1016/j.jtice.2015.02.018

75. Kondo, T.; Kameshima, T.; Kawai, T. Chem. Lett. 2008, 37, 828-829. doi:10.1246/cl.2008.828

76. Delbecq, F.; Takahashi, Y.; Kondo, T.; Corbas, C. C.; Ramos, E. R.; Len, C. Catal. Commun. 2018, 110, 74-78. doi:10.1016/j.catcom.2018.03.020

77. Nongbe, M. C.; Ekou, T.; Ekou, L.; Yao, K. B.; Le Grognec, E.; Felpin, F.-X. Renewable Energy 2017, 106, 135-141. doi:10.1016/j.renene.2017.01.024 


\section{License and Terms}

This is an Open Access article under the terms of the Creative Commons Attribution License (http://creativecommons.org/licenses/by/4.0). Please note that the reuse, redistribution and reproduction in particular requires that the authors and source are credited.

The license is subject to the Beilstein Journal of Organic Chemistry terms and conditions:

(https://www.beilstein-journals.org/bjoc)

The definitive version of this article is the electronic one which can be found at:

$\underline{\text { doi:10.3762/bjoc. } 14.253}$ 